\title{
Os reflexos da crise hídrica brasileira na estrutura de custos das empresas do setor de energia elétrica
}

Ângelo Wesley de Sousa Falcão
MBA em andamento em Controladoria e Gerência Contábil pela Universidade de
Fortaleza - UNIFOR
Contador e Consultor fiscal na KPMG Brasil
Avenida I, 1661. Prefeito José Walter. Fortaleza/CE. CEP: 60.750-080
E-mail: angwesley@hotmail.com
Rosângela Venâncio Nunes
Mestrado em Logística e Pesquisa Operacional pela Universidade Federal do Ceará -
UFC
Professora do Centro Universitário Estácio do Ceará
Rua Sebastião de Abreu, 177, apto 107 C. Maraponga. Fortaleza/CE. CEP: 60.710-830
E-mail: angelnuness@gmail.com

Charles Washington Costa de Assis Especialização em MBA em Gestão Financeira e Controladoria pela Faculdade Integrada do Ceará Professor do Centro Universitário Estácio do Ceará Rua Sebastião de Abreu, 177, apto 107 C. Maraponga. Fortaleza/CE. CEP: 60.710-830 E-mail: charles-cont@hotmail.com

Nayana de Almeida Adriano Doutorado em andamento em Administração e Controladoria pela Universidade Federal do Ceará - UFC Professora do Centro Universitário Estácio do Ceará Rua Gustavo Sampaio, 1413, apto 1701. Parquelândia. Fortaleza/CE. CEP: 60.455-001 E-mail: nayanaadriano@hotmail.com

Alexandra Alencar Siebra Doutorado em andamento em Administração e Controladoria pela Universidade Federal do Ceará - UFC Coordenadora do curso MBA em Gestão Financeira e Controladoria do Centro Universitário Estácio do Ceará Av. Santos Dumont 3665, apto 1201. Aldeota. Fortaleza/CE. CEP: 60.150-900 E-mail: alexandra.siebra@estacio.br

\section{RESUMO}

Ao longo dos anos, o Brasil enfrenta uma grave crise hidrológica que afeta as diversas camadas sociais e setores econômicos do país. Dentre elas, o setor elétrico brasileiro dependente direto dos recursos hídricos em sua cadeia de suprimentos - vivencia uma situação de risco operacional hídrico, tendo em vista os baixos níveis de água nos 
Os reflexos da crise hídrica brasileira na estrutura de custos das empresas do setor de energia

elétrica

Ângelo Wesley de Sousa Falcão, Rosângela Venâncio Nunes, Charles Washington Costa de Assis, Nayana de Almeida Adriano, Alexandra Alencar Siebra

reservatórios e, como consequência, redução na geração de energia nas usinas hidrelétricas. Nesse sentido, este estudo tem por objetivo analisar os reflexos da crise hídrica nos indicadores ligados à estrutura de custos das empresas que compõem a cadeia produtiva do setor elétrico brasileiro nos anos de 2011 a 2015. Para a análise de resultados, utilizou-se uma amostra final de 15 empresas do setor elétrico brasileiro, a qual se avaliou mediante análise de conteúdo dos relatórios anuais, em que se coletaram os indicadores econômicos, operacionais e da Global Reporting Initiative (GRI). Observou-se, a partir da análise, que os setores de geração e transmissão apresentaram reflexos favoráveis com a crise em seus indicadores econômicos e reflexos desfavoráveis e favoráveis em seus indicadores operacionais. Já o setor de distribuição apresentou reflexos balanceados, com variações favoráveis e desfavoráveis nos indicadores econômicos e, em suma, favoráveis nos operacionais, sendo o setor com afetações mais relevantes, consolidando as alterações de custos da cadeia e conciliando essas alterações na comercialização de energia junto ao consumidor final.

Palavras-Chave: Crise hídrica. Setor elétrico brasileiro. Estrutura de custos.

\section{Reflections of the Brazilian water crisis on the cost structure of companies in the electric power sector}

\section{ABSTRACT}

Last years, Brazil faced an aggravated hydrological crisis, which affects the various social pieces and economic sectors of the country. Among them, the Brazilian electricity sector, directly dependent on water resources in its supply chain, experiences a situation of hydrological operational risk, due to the low levels of water in the reservoirs and, as a consequence, reduction in the generation of energy in the hydroelectric plants. In this logic, this study aims to analyze the effects of the water crisis on the indicators related to the cost structure of the companies that make up the productive chain of the Brazilian electricity sector, from 2011 to 2015 . The methodology used to carry out the study included qualitative research, quantitative, bibliographic, documentary and exploratory. For the analysis of results, a final sample of 15 companies of the Brazilian electric sector was used, which was evaluated through content analysis of the annual reports, in which the economic, operational and Global Reporting Initiative (GRI) indicators were collected. It was observed from the analysis that the generation and transmission sectors presented favorable effects with the crisis on their economic indicators and unfavorable and favorable effects on their operational indicators. On the other hand, the distribution sector presented balanced effects, with favorable and unfavorable changes in the economic indicators and, in the end, favorable ones in the operational ones, being the sector with more important affectations, consolidating the 
Os reflexos da crise hídrica brasileira na estrutura de custos das empresas do setor de energia elétrica

Ângelo Wesley de Sousa Falcão, Rosângela Venâncio Nunes, Charles Washington Costa de Assis, Nayana de Almeida Adriano, Alexandra Alencar Siebra

changes of costs of the chain and reconciling these changes in the commercialization of energy together to the final consumer.

Keywords: Water crisis. Brazilian electricity sector. Cost structure.

\section{INTRODUÇÃO}

A energia elétrica se tornou um dos bens essenciais para o avanço econômico e social no mundo moderno. Seja da geração de energia pela força das águas, dos ventos ou da energia do sol e de recursos fósseis, a eletricidade surge como uma solução para o desenvolvimento das sociedades diante do alto nível tecnológico que se vivencia atualmente.

O Brasil dispõe de grande diversidade de fontes primárias para a geração de eletricidade, dentre as quais se podem citar: a hidráulica, a biomassa, a eólica, o gás natural, o petróleo, a nuclear e o carvão. Apesar dessa diversidade de fontes energéticas, a matriz elétrica brasileira possui origem predominantemente renovável, em que a geração hidráulica, no ano de 2015 , respondeu por $65,2 \%$ da oferta interna (Brasil, 2015). O potencial energético proveniente da geração hidrelétrica fica evidente quando se verifica a quantidade abundante de recursos hídricos do país, que possui em torno de $12 \%$ de toda a água doce do planeta, segundo o Ministério do Meio Ambiente (Brasil, 2015).

Em oposição ao seu potencial hídrico, o Brasil vivenciou, mais intensamente nos anos de 2014 e 2015, uma crise hídrica e energética nacional. As condições hidrológicas vivenciadas nesses anos prejudicaram não somente o abastecimento de água para a população, como também a geração de energia nas usinas hidrelétricas do país que, para isso, utilizam a água dos rios.

Segundo Galvão e Bermann (2015): "[...] a redução dos níveis de precipitação ocorrida no período, com a consequente redução das afluências naturais nos reservatórios, acarretaram a necessidade de recorrer à geração termoelétrica". 
Os reflexos da crise hídrica brasileira na estrutura de custos das empresas do setor de energia elétrica

Ângelo Wesley de Sousa Falcão, Rosângela Venâncio Nunes, Charles Washington Costa de Assis, Nayana de Almeida Adriano, Alexandra Alencar Siebra

Dessa forma, a fim de garantir a segurança energética brasileira, o governo optou por comprar energia por meio das usinas termoelétricas, que geram energia com um custo maior que as usinas hidrelétricas (Galvão \& Bermann, 2015).

Uma vez alterado o custo de geração da energia elétrica, toda a cadeia produtiva do setor sofreu alterações em suas estruturas econômicas. Dessa forma, a mudança nos custos de geração de energia impactou diretamente a estrutura de custos das empresas transmissoras e das distribuidoras de energia e, consequentemente, do consumidor final.

Silva (2015) analisou, em seu estudo, o desempenho econômico-financeiro das indústrias brasileiras de energia elétrica listadas na B3, no período de 2009 a 2013, e concluiu que a crise de 2012 do setor elétrico produziu alterações relevantes nos indicadores de liquidez, endividamento, rentabilidade e atividades dessas empresas, com variações consideradas positivas na liquidez e atividade e negativas na rentabilidade e endividamento das empresas, com o indicador de rentabilidade sofrendo as maiores reduções durante a crise e demonstrando variações positivas a partir do ano de 2013, visto como uma reação à crise.

No contexto da crise hídrica, as empresas pertencentes ao setor elétrico que se constituem na forma de sociedade por ações de capital aberto, além da necessidade de gerenciar os recursos hídricos disponíveis, também se veem obrigadas a enfrentar as inconstâncias do mercado de capitais. Com isso, a B3 se torna uma das principais fontes expositoras de informações de desempenho aos stakeholders dessas empresas e sociedade em geral.

Por meio da contextualização até então apresentada, o presente artigo tem como objetivo geral analisar os reflexos da crise hídrica brasileira na estrutura de custos das empresas do setor de energia elétrica nos anos de 2011 a 2015.

O tema deste trabalho passa a ser justificado por estar inserido no contexto econômico e social brasileiro, tendo em vista que a crise hídrica, acarretada a princípio pelo baixo nível de precipitações chuvosas, gerou reflexos no abastecimento de água 
Os reflexos da crise hídrica brasileira na estrutura de custos das empresas do setor de energia elétrica

Ângelo Wesley de Sousa Falcão, Rosângela Venâncio Nunes, Charles Washington Costa de Assis, Nayana de Almeida Adriano, Alexandra Alencar Siebra

da sociedade em geral e dificuldades para o desenvolvimento das empresas do setor elétrico. Estudar a crise hídrica permite verificar as causas da elevação do preço da energia pago pelo consumidor final da cadeia de suprimentos do setor elétrico brasileiro, sendo um item de extrema necessidade a todas as cadeias produtivas e a todos os segmentos econômicos e sociais. No que tange ao contexto corporativo, estudar a cadeia produtiva do setor elétrico brasileiro, antes e conjuntamente à crise hídrica, admite analisar como as empresas do setor gerenciam os recursos hídricos disponíveis à sociedade em contrapartida do seu desenvolvimento econômico e como reagem economicamente diante de situações de risco hídrico.

\section{REFERENCIAL TEÓRICO}

\subsection{A cadeia do setor elétrico brasileiro}

Até alcançar o cliente final, todo produto passa por um processo de produção que envolve diversas linhas de operação produtiva. Cada linha de operação necessita de outra para que possa dar continuidade ao seu processo, formando, assim, uma rede interconectada. Essa rede é composta por todas as organizações envolvidas nos fluxos produtivos, desde a fonte primária até o consumidor final. É o que se pode caracterizar como cadeia de suprimentos (ou Supply Chain).

A Figura 1 a seguir ilustra, de forma simplificada, os setores e agentes que compõem a cadeia de suprimentos do setor elétrico brasileiro de natureza hidráulica. 
Os reflexos da crise hídrica brasileira na estrutura de custos das empresas do setor de energia elétrica

Ângelo Wesley de Sousa Falcão, Rosângela Venâncio Nunes, Charles Washington Costa de Assis, Nayana de Almeida Adriano, Alexandra Alencar Siebra

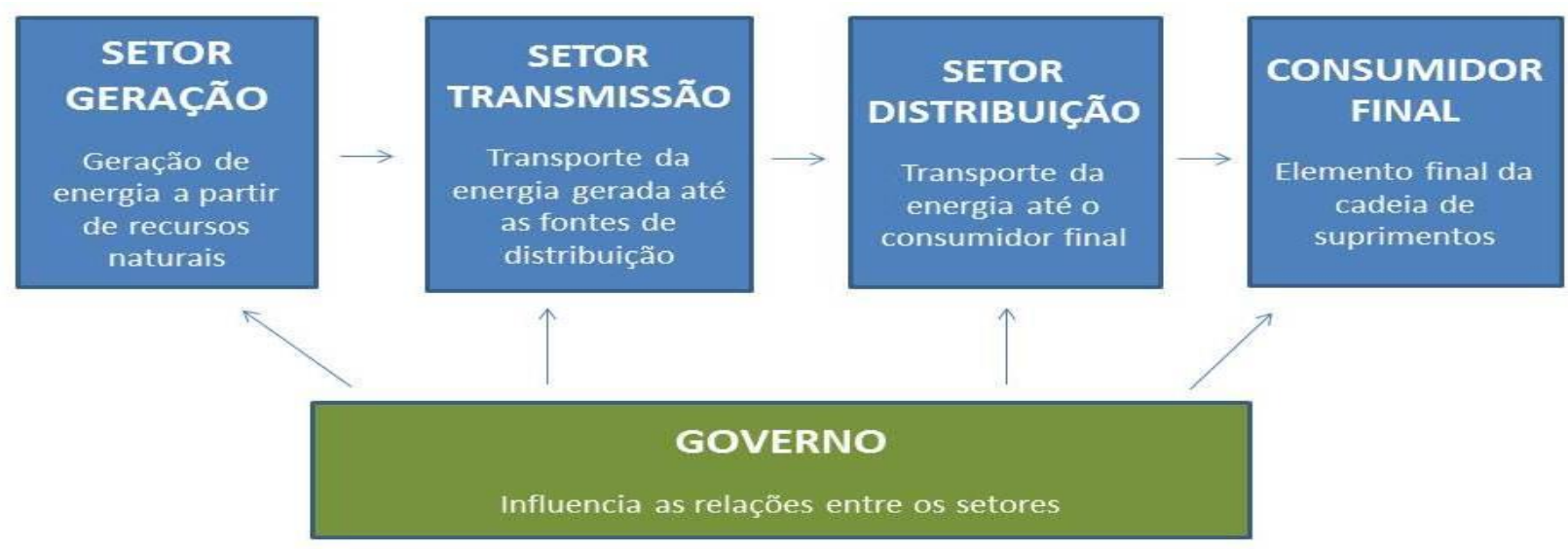

Figura 1. Cadeia do setor elétrico brasileiro

Fonte: Elaborada pelos autores.

Na Figura 1, observa-se o processo produtivo da cadeia de suprimentos do setor elétrico brasileiro a partir da energia primária. As empresas geradoras transformam a energia hidráulica em energia elétrica e a disponibilizam ao sistema de transmissão. Neste sistema, as empresas transmissoras são responsáveis por transportar a energia por longas distâncias, até as empresas distribuidoras. As distribuidoras, por sua vez, possibilitam o alcance da energia às unidades consumidoras finais.

A Figura 1 evidencia que, em uma visão ampla, os segmentos do mercado e do consumidor final sofrem influências das decisões governamentais. Assim, os setores da cadeia produtiva do setor elétrico estão sujeitos ao risco regulatório governamental.

O risco regulatório pode ser entendido como um componente específico do risco de empresas sujeitas a regulação, decorrente de fatores como modificações na estrutura legal, atualizações tarifárias e tantas outras formas de imposição de limites e restrições que o governo pode conferir na busca de preservação e defesa do interesse público. As empresas que atuam na prestação de serviços públicos, pela própria característica de seus serviços, estão submetidas a forte influência de políticas regulatórias (Taffarel, Silva, \& Clemente, 2016). 
Os reflexos da crise hídrica brasileira na estrutura de custos das empresas do setor de energia elétrica

Ângelo Wesley de Sousa Falcão, Rosângela Venâncio Nunes, Charles Washington Costa de Assis, Nayana de Almeida Adriano, Alexandra Alencar Siebra

Apesar das diversas políticas públicas de regulação do mercado de energia elétrica no Brasil, o agente governo não será explorado com maiores detalhes neste estudo, tanto na parte teórica quanto na parte aplicada, por não se tratar do foco da pesquisa.

Ao final desta reflexão sobre gestão da cadeia de suprimentos e cadeia de suprimentos do setor elétrico brasileiro, é perceptível que, para as empresas que compõem o setor elétrico, qualquer mudança no processo de geração de energia elétrica produz uma reação em cadeia, afetando diretamente os custos de aquisição e venda do produto no país, que, por sua vez, são repassados ao consumidor final.

\subsection{Indicadores de desempenho econômico para análise estrutural de cadeia de suprimentos}

Com as constantes mudanças no mercado, monitorar o desempenho da organização se traduz como fundamental. Para isso, faz-se necessário o uso de técnicas de análise de dados. Dentre as diversas, pode-se citar a realizada por meio de índices ou indicadores econômico-financeiros-operacionais, bastante utilizados para medir e analisar, em visão ampla ou particular, o desempenho das empresas dentro de uma dimensão empresarial.

De acordo com MacArthur (1996, apud Beuren \& Marcello, 2016), as medidas de desempenho quantificam como as atividades empresariais estão sendo realizadas, a fim de comparar com as metas especificadas. A análise do desempenho se constitui em um conjunto de etapas, estabelecidas previamente, com a finalidade de se obter indicadores e informações que sirvam de referência para acompanhar, avaliar e projetar a evolução do desempenho das empresas (Callado, Callado, Moller, \& Neutzling, 2009).

Durski (2003) apresenta em seu estudo um modelo de indicadores destinados a mensurar resultados e apoiar na tomada de decisões relacionadas à cadeia produtiva, os quais, dependendo da especificidade da análise, poderão ser incorporados como novos indicadores aos grupos. 
Os reflexos da crise hídrica brasileira na estrutura de custos das empresas do setor de energia elétrica

Ângelo Wesley de Sousa Falcão, Rosângela Venâncio Nunes, Charles Washington Costa de Assis, Nayana de Almeida Adriano, Alexandra Alencar Siebra

O modelo proposto por Durski (2003), direcionado por Bonelli e Fonseca (2011), considera: (a) a necessidade de estabelecer indicadores para os fatores que condicionam a competitividade, relacionados à extensão empresarial, como produtividade, capacidade gerencial, qualidade etc.; (b) a necessidade de acompanhamento do todo (global), não desconhecendo o desempenho individual de cada elo; e (c) a necessidade de um modelo com indicadores passíveis de comparação em relação a si próprios ou em relação à sua evolução comparada aos indicadores equivalentes de indústrias similares (Durski, 2003).

De acordo com Shimizu, Wainai e Naigai (1991, apud Durski, 2003), o desenvolvimento de um modelo de indicadores de produtividade deve considerar as seguintes necessidades: (a) medir os indicadores tanto no nível físico quanto no estratégico; (b) utilizar, além do resultado da receita, o resultado do valor adicionado, permitindo analisar a produtividade tendo por base o resultado gerado pela empresa; e (c) analisar os indicadores de produtividade juntamente com os indicadores econômicos e financeiros, possibilitando o melhor e mais seguro gerenciamento (Durski, 2003).

Dessa forma, uma análise do desempenho empresarial por meio de índices e indicadores fornece aos stakeholders informações significativas quanto à situação passada, presente e de tendência evolutiva do negócio.

Para cada segmento do mercado, podem ser listados grupos distintos de indicadores de desempenho, sendo observadas as características específicas de cada segmento e os resultados que se pretende analisar. A Figura 2, a seguir, apresenta os grupos de indicadores que serão utilizados neste estudo, baseando-se nos grupos propostos por Durski (2003). 
Os reflexos da crise hídrica brasileira na estrutura de custos das empresas do setor de energia elétrica

Ângelo Wesley de Sousa Falcão, Rosângela Venâncio Nunes, Charles Washington Costa de Assis, Nayana de Almeida Adriano, Alexandra Alencar Siebra

\begin{tabular}{|c|c|c|}
\hline $\begin{array}{c}\text { GRUPOS DE } \\
\text { INDICADORES }\end{array}$ & DESCRIÇÃO & EXEMPLOS \\
\hline $\begin{array}{c}\text { INDICADORES } \\
\text { ECONÔMICOS }\end{array}$ & $\begin{array}{c}\text { Sinalizam o comportamento das diferentes } \\
\text { variveis econômicas empresariais, propiciando } \\
\text { a compreensão da situação empresarial } \\
\text { (passada e presente) e delineando as tendências } \\
\text { futuras do negócio. }\end{array}$ & $\begin{array}{c}\text { Receita bruta, custos dos } \\
\text { serviços, EBITDA, ROI, } \\
\text { ROE etc. }\end{array}$ \\
\hline $\begin{array}{c}\text { INDICADORES } \\
\text { OPERACIONAIS }\end{array}$ & $\begin{array}{c}\text { Mensuram a eficiência com que a empresa } \\
\text { conduz suas operações, a fim de apresentar os } \\
\text { resultados do processo produtivo geral do } \\
\text { negócio. }\end{array}$ & $\begin{array}{c}\text { Capacidade de produção, } \\
\text { capacidade de venda, } \\
\text { preço médio de venda por } \\
\text { quantidade vendida etc. }\end{array}$ \\
\hline $\begin{array}{c}\text { INDICADORES } \\
\text { GLOBAL REPORTING } \\
\text { INITIATIVE (GRI) }\end{array}$ & $\begin{array}{c}\text { Apresentam as informações de desempenho } \\
\text { econômico, ambiental e social das empresas, } \\
\text { focando a divulgação de informações aos } \\
\text { diversos stakeholders. }\end{array}$ & $\begin{array}{c}\text { Indicadores de desem- } \\
\text { penho econômico, indica- } \\
\text { dores setoriais etc. }\end{array}$ \\
\hline
\end{tabular}

Figura 2. Grupos de indicadores de desempenho empresarial

Fonte: Adaptado de Durski (2003), Gitman (2010), Chiavenato (2014) e GRI (2015).

"A análise de índices envolve métodos de cálculo e interpretação de índices financeiros para analisar e monitorar o desempenho da empresa" (Gitman, 2010), grifo do autor). Além disso, mediante a classificação por índices, é possível ainda comparar índices de empresas que se enquadram no mesmo ramo ou tamanho (Chiavenato, 2014).

De acordo com Dias (2008), os indicadores operacionais, ou de produtividade, são os indicadores encontrados dentro dos processos produtivos e que se relacionam com a utilização de recursos na geração de produtos e serviços, como, por exemplo, capacidade de produção.

Os indicadores GRI surgiram com a finalidade de medir, divulgar e prestar contas aos diversos stakeholders sobre o desempenho das organizações, a fim de alcançar o objetivo do desenvolvimento sustentável (GRI, 2015). Diferentemente do que se imagina, os relatórios de sustentabilidade estruturados pela GRI também fornecem 
Os reflexos da crise hídrica brasileira na estrutura de custos das empresas do setor de energia elétrica

Ângelo Wesley de Sousa Falcão, Rosângela Venâncio Nunes, Charles Washington Costa de Assis, Nayana de Almeida Adriano, Alexandra Alencar Siebra

informações de desempenho econômico, além dos indicadores ambiental e social, permitindo analisar por completo as variações do negócio.

No Brasil, a difusão das diretrizes da GRI e de sua aplicação conta com a parceria entre UniEthos, uma associação independente, sem fins lucrativos, dedicada integralmente à educação por meio do desenvolvimento de estudos, pesquisas e capacitação em RSE (Relatório de Sustentabilidade Empresarial), o Centro de Estudos em Sustentabilidade (GVces) da Escola de Administração de Empresas da Fundação Getúlio Vargas (FGV-EAESP) e BSD Consulting Brasil, empresa especializada em sustentabilidade, este consórcio que foi o primeiro no mundo a ser certificado para ministrar a oficina de capacitação em GRI (Uniethos, 2014).

No que diz respeito aos documentos que compõem a estrutura de relatórios da GRI, todos são desenvolvidos por meio do consenso entre os stakeholders, como empresas, investidores, trabalhadores, sociedade civil, contadores, comunidade científica, entre outros, além de estarem sujeitos a testes e melhoria contínua (GRI, 2013).

"A GRI irá rever continuamente a aplicabilidade e clareza de todos os princípios para a elaboração dos relatórios para assegurar que são relevantes e compreensíveis para as organizações relatoras e utilizadoras" (Costa, 2012).

As Diretrizes para Elaboração de Relatórios de Sustentabilidade da GRI estão divididas em duas partes. A primeira parte fala da definição de conteúdo, qualidade e limite do relatório, a qual define os princípios para definição do conteúdo, que são: materialidade, inclusão dos stakeholders, contexto da sustentabilidade e abrangência. Também define os princípios para assegurar a qualidade do relatório, que são: equilíbrio, comparabilidade, exatidão, periodicidade, clareza e a confiabilidade; por último, as orientações para o estabelecimento do limite do relatório (GRI, 2013).

A segunda parte aborda o conteúdo do relatório que se divide em três categorias: (1) Perfil em que constam informações que fornecem o contexto geral para a compreensão do desempenho organizacional, incluindo sua estratégia, perfil e 
Os reflexos da crise hídrica brasileira na estrutura de custos das empresas do setor de energia elétrica

Ângelo Wesley de Sousa Falcão, Rosângela Venâncio Nunes, Charles Washington Costa de Assis, Nayana de Almeida Adriano, Alexandra Alencar Siebra

governança; (2) Informação sobre a forma de gestão, dados cujo objetivo é explicitar o contexto no qual deve ser interpretado o desempenho da organização numa área específica; e (3) Indicadores de desempenho que expõem informações sobre o desempenho econômico, ambiental e social da organização passíveis de comparação (GRI, 2013).

Os indicadores de desempenho podem ser essenciais e adicionais. São ao todo 85 indicadores, dos quais cinquenta e cinco são essenciais. Como está proposto na GRI (2013), "Todos os indicadores foram desenvolvidos pela GRI em processos multistakeholders, e aqueles designados como essenciais são geralmente aplicáveis e considerados relevantes pela maioria das organizações". Aqueles indicadores considerados adicionais representam práticas emergentes ou tratam de temas que podem ser relevantes para algumas organizações; entretanto, para outras não (GRI, 2013). Os indicadores de desempenho essenciais e adicionais estão contidos na dimensão econômica, social e ambiental do relatório de sustentabilidade.

A GRI (2013) destaca que os indicadores de desempenho econômico "se refere[m] aos impactos da organização sobre as condições econômicas de seus stakeholders e sobre os sistemas econômicos em nível local, nacional, e global". Devese fornecer um relato acerca da forma de gestão com referência ao desempenho econômico, à presença de mercado e aos impactos econômicos indiretos (GRI, 2013).

Os indicadores de desempenho ambiental, conforme a GRI (2013), "refere[m] aos impactos da organização sobre sistemas naturais vivos e não vivos, incluindo ecossistemas, terra, ar e água", destacando-se os seguintes aspectos: materiais, energia, água, biodiversidade, emissões, efluentes e resíduos, produtos e serviços, conformidade, transporte e geral.

O indicador de desempenho social se refere aos impactos da organização nos sistemas sociais nos quais opera; trabalha-se a questão das práticas trabalhistas e do trabalho decente, os direitos humanos e a sociedade, além da responsabilidade pelo produto (GRI, 2013). 
Os reflexos da crise hídrica brasileira na estrutura de custos das empresas do setor de energia elétrica

Ângelo Wesley de Sousa Falcão, Rosângela Venâncio Nunes, Charles Washington Costa de Assis, Nayana de Almeida Adriano, Alexandra Alencar Siebra

Os três grupos de indicadores que compõem a estrutura dos relatórios de sustentabilidade se tornam bastante úteis para a delimitação do conteúdo, conforme suas características, além de fixar o montante de informações a serem divulgadas.

Conforme a evolução dos relatórios da GRI, ocorrem, consequentemente, mudanças em algum aspecto dos seus grupos de indicadores, adequando-os às novas práticas ou às necessidades de implementações. Para obter os dados relevantes à pesquisa, foram analisadas as versões GRI G4 e anteriores desta modalidade de relatório.

\subsection{A crise hídrica no Brasil: causas e consequências no setor elétrico}

O Brasil enfrentou um quadro hidrológico bastante crítico entre os anos de 2011 a 2015. É controverso pensar que um país com os maiores percentuais de água doce do planeta possa passar por essa situação, já que o Brasil detém 12\% de toda a água doce do planeta (Brasil, 2015). Porém, analisando as causas da crise, torna-se clara essa possibilidade.

A Figura 3, a seguir, apresenta as principais causas e consequências da crise brasileira, intensificada em 2014 e 2015.

\begin{tabular}{|c|c|}
\hline \multicolumn{2}{|c|}{ PRINCIPAIS CAUSAS E CONSQUÊNCIAS DA CRISE HIDRÍCA } \\
\hline CAUSAS & CONSEQUÊNCIAS \\
\hline $\begin{array}{c}\text { Falta de precipitações chuvosas } \\
\text { regulares (estiagem) }\end{array}$ & $\begin{array}{c}\text { Diminuição do nível de água } \\
\text { nos reservatórios }\end{array}$ \\
\hline $\begin{array}{c}\text { Degradação dos recursos naturais } \\
\text { Consumo excessivo de água }\end{array}$ & $\begin{array}{c}\text { Insueiência de água para } \\
\text { abastecimento da população }\end{array}$ \\
\hline $\begin{array}{c}\text { Desperdício de água durante o } \\
\text { abastecimento da população }\end{array}$ & $\begin{array}{c}\text { Redução na quantidade de energia geradas nas } \\
\text { usinas hidrelétricas }\end{array}$ \\
\hline
\end{tabular}

Figura 3. Principais causas e consequências da crise hídrica brasileira

Fonte: Adaptado de Almeida e Benassi (2015), Pereira Filho (2015), Cazarré (2016) e Pena (2016). 
Os reflexos da crise hídrica brasileira na estrutura de custos das empresas do setor de energia elétrica

Ângelo Wesley de Sousa Falcão, Rosângela Venâncio Nunes, Charles Washington Costa de Assis, Nayana de Almeida Adriano, Alexandra Alencar Siebra

A falta de precipitações chuvosas é tida como uma das principais causas da crise hídrica brasileira. Nos últimos anos, principalmente em 2014, os níveis das precipitações chuvosas ficaram bem abaixo do esperado e, devido a isso, os reservatórios em todo o país, principalmente na região Sudeste, mantiveram baixas históricas nos níveis de água (Pena, 2016).

Para Almeida e Benassi (2015), analisando as causas da crise hídrica na região Sudeste do Brasil, a escassez de chuvas tem a contribuição do desmatamento dos biomas terrestres regionais e a deterioração dos biomas aquáticos regionais impulsionados pelo avanço da urbanização que incorpora áreas de mananciais. Além disso, o processo de urbanização, acompanhado do aumento da poluição atmosférica e desmatamento, permitem a formação de ilhas de calo.Com isso, aumenta a temperatura dos microclimas desprovidos de nebulosidades, devido à diminuição (entre 2014 e 2015) das massas de ar frio formadoras de chuvas.

Outro fator para a causa da crise hídrica é o desperdício. Além do consumo exagerado, grande parcela de água já tratada em estações próprias são desperdiçadas $(36,4 \%)$ durante o transporte para o consumidor, tendo como responsáveis os vazamentos nas tubulações, devido ao uso de encanamentos velhos, e as ligações clandestinas (Cazarré, 2016).

A partir do exposto, pode-se destacar que a crise hídrica provocou sérias consequências para o país, desde a falta de água para abastecimento da população até o aumento nas contas de energia elétrica do consumidor final.

No Brasil, as hidrelétricas são responsáveis por cerca de $70 \%$ da geração de energia elétrica, contudo, devido à estiagem, esse percentual produtivo sofreu drástica redução (Pereira Filho, 2015). Devido ao declínio sistemático do volume de água armazenada nos reservatórios das hidrelétricas do país, houve uma "carbonização" do sistema de geração de energia com o acionamento das usinas térmicas (Goldermberg, 2015). 
Os reflexos da crise hídrica brasileira na estrutura de custos das empresas do setor de energia elétrica

Ângelo Wesley de Sousa Falcão, Rosângela Venâncio Nunes, Charles Washington Costa de Assis, Nayana de Almeida Adriano, Alexandra Alencar Siebra

Para o consumidor final, a consequência principal da crise hídrica foi a elevação das contas de luz, com a implantação do sistema de bandeiras tarifárias em 2015. Nesse sistema, o custo de geração é sinalizado por cores, onde cada cor, que poderá ser verde, amarela ou vermelha, representará o custo da energia, tendo por base as condições para a geração de eletricidade (ANEEL, 2016). A bandeira verde evidencia condições favoráveis para a geração de energia elétrica, não acarretando custo adicional na tarifa. A bandeira amarela sinaliza um quadro menos favorável para a geração, enquanto que a bandeira vermelha evidencia a utilização de usinas térmicas, que possuem um custo mais caro que as hidrelétricas.

De acordo com a Agência Nacional de Energia Elétrica (ANEEL, 2016), as bandeiras tarifárias objetivam mostrar aos consumidores o custo real para a geração de energia elétrica em determinado período. Para o cálculo do preço a ser pago nesse sistema, o consumo (em quilowatts/hora, $\mathrm{KWh}$ ) é multiplicado pelo valor da bandeira tarifária (em reais), caso ela seja amarela ou vermelha no período, sendo aplicada a todos os consumidores (ANEEL, 2016).

Para o setor elétrico, a principal consequência da crise hídrica foi a desestruturação dos fluxos econômicos das empresas desse setor. Como evidenciado, devido ao baixo nível de água nos reservatórios das usinas hidrelétricas e a consequente diminuição na geração de energia nessa matriz, outras fontes primárias de geração - e com custo maior - tiveram que ser acionadas para evitar um colapso no fornecimento de energia do país. Com isso, as empresas geradoras se viram obrigadas a comprar energia de fontes mais caras para cumprir seus contratos de fornecimento de energia, alterando seus custos e resultados do período.

Durante um período de crise, seja econômica, social ou hídrica, muitos podem ser os impactos para uma cadeia produtiva. Por meio da análise de desempenho empresarial mediante indicadores, é possível analisar, por exemplo, o comportamento empresarial em situações de crise de mercado. Voltando-se para o setor elétrico, tornase possível, por meio desta técnica, verificar como as empresas da cadeia produtiva 
Os reflexos da crise hídrica brasileira na estrutura de custos das empresas do setor de energia elétrica

Ângelo Wesley de Sousa Falcão, Rosângela Venâncio Nunes, Charles Washington Costa de Assis, Nayana de Almeida Adriano, Alexandra Alencar Siebra

reagiram diante dos riscos hidrológicos vivenciados no período de 2011 a 2015, evidenciando suas consequências.

O referencial teórico até aqui explanado é importante para dar base à parte aplicada desta pesquisa, por intermédio de uma análise exploratória e quantitativa, aplicada no setor de energia elétrica brasileiro.

\section{METODOLOGIA}

Este artigo tem como objetivo identificar, analisar e refletir sobre os reflexos ocasionados pela crise hídrica brasileira na estrutura de custos das empresas pertencentes ao setor elétrico, listadas no site da Brasil, Bolsa, Balcão (B3), analisando o período de 2011 a 2015. A pesquisa é classificada como qualitativa, quantitativa, bibliográfica, documental e exploratória.

Para a análise dos dados obtidos, foi também realizada uma análise de conteúdo. Para Silverman (2009), "A análise do conteúdo é um método aceito de investigação textual, sobretudo no campo das comunicações de massa".

Como fonte de dados secundários, utilizaram-se os demonstrativos e relatórios anuais de 37 empresas listadas na B3, pertencentes ao segmento de energia elétrica e que compõem a cadeia produtiva deste setor no Brasil, distribuídas entre geradoras, transmissoras e distribuidoras de energia, durante os anos de 2011 a 2015, extraídos diretamente do website oficial da B3 e dos websites dessas empresas.

A Tabela 1, a seguir, mostra as 37 empresas listadas no site da B3 e analisadas neste estudo, segregadas por área de atuação e em ordem alfabética. 
Os reflexos da crise hídrica brasileira na estrutura de custos das empresas do setor de energia

elétrica

Ângelo Wesley de Sousa Falcão, Rosângela Venâncio Nunes, Charles Washington Costa de Assis, Nayana de Almeida Adriano, Alexandra Alencar Siebra

Tabela 1

Relação prévia das empresas utilizadas no estudo

\begin{tabular}{cl}
\hline \multicolumn{1}{c}{ EMPRESAS GERADORAS DE ENERGIA ELÉTRICA } \\
\hline 1 & AES TIETÊ ENERGIA S.A. \\
2 & AFLUENTE G -AFLUENTE GERAÇÃO DE ENERGIA ELÉTRICA S.A. (EXCLUÍDA DA ANÁLISE) \\
3 & BAESA - ENERGÉTICA BARRA GRANDE S.A. (EXCLUIIDA DA ANÁLISE) \\
4 & CEMIG GT - CEMIG GERAÇÃO E TRANSMISSÃO S.A. (EXCLUÍDA DA ANÁLISE) \\
5 & CESP - COMPANHIA ENERGÉTICA DE SÃO PAULO \\
6 & CEEE-GT - COMPANHIA ESTADUAL DE GERAÇÃO E TRANSMISSÃO DE ENERGIA ELÉTRICA \\
7 & CPFL GERAÇÃO DE ENERGIA S.A. (EXCLUÍDA DA ANÁLISE) \\
8 & DUKE ENERGY INTERNACIONAL, GERAÇÃO PARANAPANEMA S.A. \\
9 & EMAE - EMPRESA METROPOLITANA DE ÁGUAS E ENERGIA S.A. (EXCLUÍDA DA ANÁLISE) \\
10 & INVESTCO S.A. (EXCLUÍDA DA ANÁLISE) \\
11 & PROMAN - PRODUTORES ENERGÉTICOS DE MANSO S.A. (EXCLUÍDA DA ANÁLISE) \\
12 & TRACTEBEL ENERGIA S.A.
\end{tabular}

EMPRESAS TRANSMISSORAS DE ENERGIA ELÉTRICA

1 AFLUENTE T - AFLUENTE TRANSMISSÃO DE ENERGIA ELÉTRICA S.A.

2 CACHOEIRA PAULISTA TRANSMISSORA DE ENERGIA S.A. (EXCLUÍDA DA ANÁLISE)

3 CTEEP - COMPANHIA DE TRANSMISSÃO DE ENERGIA ELÉTRICA PAULISTA

4 TAESA - TRANSMISSORA ALIANÇA DE ENERGIA ELÉTRICA S.A.

\section{EMPRESAS DISTRIBUIDORAS DE ENERGIA ELÉTRICA}

1 AES SUL DISTRIBUIDORA GAUCHA DE ENERGIA S.A.

2 AMPLA - AMPLA ENERGIA E SERVICOS S.A. (EXCLUÍDA DA ANÁLISE)

3 BANDEIRANTE ENERGIA S.A. (EXCLUÍDA DA ANÁLISE)

4 CEMIG DISTRIBUICAO S.A. (EXCLUÍDA DA ANÁLISE)

5 CELPA - CENTRAIS ELÉTRICAS DO PARÁ S.A. (EXCLUÍDA DA ANÁLISE)

6 COELBA - COMPANHIA DE ELETRICIDADE DO ESTADO DA BAHIA

7 CEB - COMPANHIA ENERGÉTICA DE BRASÍLIA (EXCLUÍDA DA ANÁLISE)

8 CELPE - COMPANHIA ENERGÉTICA DE PERNAMBUCO

9 COELCE - COMPANHIA ENERGÉTICA DO CEARÁ (EXCLUÍDA DA ANÁLISE)

10 CEMAR - COMPANHIA ENERGÉTICA DO MARANHÃO (EXCLUÍDA DA ANÁLISE)

11 COSERN - COMPANHIA ENERGÉTICA DO RIO GRANDE DO NORTE

12 CEEE-D - COMPANHIA ESTADUAL DE DISTRIBUIÇÃO DE ENERGIA ELÉTRICA

13 COMPANHIA PAULISTA DE FORÇA E LUZ (EXCLUÍDA DA ANÁLISE)

14 COMPANHIA PIRATININGA DE FORÇA E LUZ (EXCLUÍDA DA ANÁLISE)

15 ELEKTRO - ELETRICIDADE E SERVIÇOS S.A.

16 ELETROPAULO METROPOLITANA ELETRICIDADE DE SÃO PAULO S.A.

17 ENERGISA MATO GROSSO DO SUL-DISTRIBUIDORA DE ENERGIA (EXCLUÍDA DA ANÁLISE)

18 ENERGISA MATO GROSSO-DISTRIBUIDORA DE ENERGIA S.A. (EXCLUÍDA DA ANÁLISE)

19 ESCELSA ESPIRITO SANTO CENTRAIS ELÉTRICAS S.A. (EXCLUÍDA DA ANÁLISE) 
Os reflexos da crise hídrica brasileira na estrutura de custos das empresas do setor de energia

elétrica

Ângelo Wesley de Sousa Falcão, Rosângela Venâncio Nunes, Charles Washington Costa de Assis, Nayana de Almeida Adriano, Alexandra Alencar Siebra

20 LIGHT SERVIÇOS DE ELETRICIDADE S.A. (EXCLUÍDA DA ANÁLISE)

21 RIO GRANDE ENERGIA S.A. (EXCLUÍDA DA ANÁLISE)

Nota. Fonte: Elaborada pelos autores (2016).

No decorrer da coleta dos dados, foi verificado que 22 empresas relacionadas na Tabela 1 não haviam disponibilizado, até a data da coleta, os relatórios ou variáveis relevantes dos cinco anos em análise. Com isso, restaram para a amostra 15 empresas, sendo 5 geradoras (AES TIETE, CESP, CEEE-GT, DUKE ENERGY e TRACTEBEL), 3 transmissoras (AFLUENTE T, CTEEP e TAESA) e 7 distribuidoras (AES SUL, COELBA, CELPE, COSERN, CEEE-D, ELEKTRO e ELETROPAULO).

Com relação à técnica para análise dos dados, fez-se uso da análise de conteúdo. A análise de conteúdo consiste em: um conjunto de técnicas de análise das comunicações visando obter, por procedimentos sistemáticos e objetivos de descrição do conteúdo das mensagens, indicadores (quantitativos ou não) que permitam a inferência de conhecimentos relativos às condições de produção/recepção (variáveis inferidas) destas mensagens (Bardin, 1977).

Após a coleta dos dados das empresas em seus relatórios, durante os anos de 2011 a 2015, procedeu-se à análise. Para que fosse possível uma comparação homogênea e viável entre as empresas, devido ao porte de cada organização, foram calculadas as variações percentuais de cada variável e indicador. Com base nisso, procedeu-se à análise comparativa das variações ocorridas nas variáveis e indicadores estudados, por ano e por segmento de mercado (geração, transmissão e distribuição).

Com base nas variações percentuais obtidas, das variáveis e indicadores econômicos, operacionais e GRI por setor de mercado, verificou-se, mediante as informações qualitativas e quantitativas, os reflexos ocorridos ao longo dos anos nesses indicadores e na estrutura de custos dessas empresas. 
Os reflexos da crise hídrica brasileira na estrutura de custos das empresas do setor de energia elétrica

Ângelo Wesley de Sousa Falcão, Rosângela Venâncio Nunes, Charles Washington Costa de Assis, Nayana de Almeida Adriano, Alexandra Alencar Siebra

\begin{tabular}{|c|c|c|}
\hline $\begin{array}{l}\text { INDICADORES } \\
\text { ECONÔMICOS }\end{array}$ & DESCRIÇÃO & FÓRMULA \\
\hline RECEITA OPERACIONAL & $\begin{array}{l}\text { Corresponde ao valor do faturamento } \\
\text { das vendas ou dos serviços. }\end{array}$ & Faturamento total do período \\
\hline RECEITA LIQQUIDA & $\begin{array}{l}\text { Corresponde ao valor do faturamento } \\
\text { das vendas ou dos serviços menos } \\
\text { deduções da receita bruta. }\end{array}$ & $\begin{array}{c}\text { Receita Bruta - deduções das } \\
\text { vendas }\end{array}$ \\
\hline $\begin{array}{l}\text { CUSTO DO SERVIÇO EM } \\
\text { ENERGIA ELÉTRICA }\end{array}$ & $\begin{array}{c}\text { Corresponde aos custos totais com } \\
\text { energia elétrica. }\end{array}$ & $\begin{array}{c}\text { Energia comprada + encargos } \\
\text { setoriais }\end{array}$ \\
\hline $\begin{array}{l}\text { CUSTO COM A } \\
\text { OPERAÇÃO }\end{array}$ & $\begin{array}{l}\text { Corresponde aos demais custos com } \\
\text { a atividade, excluindo os custos com } \\
\text { energia elétrica. }\end{array}$ & Demais custos com a operação \\
\hline $\begin{array}{c}\text { DESPESAS } \\
\text { OPERACIONAIS }\end{array}$ & $\begin{array}{c}\text { Corresponde às despesas } \\
\text { necessárias as atividades da } \\
\text { empresa. }\end{array}$ & $\begin{array}{l}\text { Despesas com vendas }+ \\
\text { despesas administrativas }\end{array}$ \\
\hline $\begin{array}{c}\text { LUCRO } \\
\text { LÍQUIDO/PREJUÍZO DO } \\
\text { EXERCÍCIO }\end{array}$ & $\begin{array}{l}\text { Corresponde ao resultado do } \\
\text { exercício depois de descontada a } \\
\text { provisão para o imposto de renda e a } \\
\text { contribuição social. }\end{array}$ & $\begin{array}{l}\text { Receitas- custos-despesas do } \\
\text { exercício- imposto de renda e } \\
\text { contribuição social }\end{array}$ \\
\hline ATIVO TOTAL & $\begin{array}{l}\text { Corresponde à soma de bens e } \\
\text { direitos da empresa. }\end{array}$ & Bens + direitos do exercício \\
\hline PATRIMÔNIO LÍQUIDO & $\begin{array}{l}\text { Corresponde ao capital próprio ou } \\
\text { que pertence aos proprietários ou } \\
\text { acionistas da empresa }\end{array}$ & Capital social + reservas \\
\hline EBTIDA & $\begin{array}{l}\text { Corresponde ao lucro antes dos } \\
\text { juros, impostos, depreciação e } \\
\text { amortização do período. }\end{array}$ & $\begin{array}{l}\text { Lucro Operacional Líquido + } \\
\text { depreciação + amortização }\end{array}$ \\
\hline $\begin{array}{l}\text { RETORNO SOBRE O } \\
\text { INVESTIMENTO - ROI }\end{array}$ & $\begin{array}{l}\text { Corresponde à eficácia gerada da } \\
\text { administração na geração de lucros a } \\
\text { partir dos ativos disponíveis. }\end{array}$ & $\begin{array}{c}\text { Lucro líquido do exercício/ativo } \\
\text { total }\end{array}$ \\
\hline $\begin{array}{l}\text { RETORNO SOBRE O } \\
\text { PATRIMÔNIO LÍQUIDO - } \\
\text { ROE }\end{array}$ & $\begin{array}{c}\text { Corresponde ao retorno obtido sobre } \\
\text { o investimento dos acionistas da } \\
\text { empresa. }\end{array}$ & $\begin{array}{l}\text { Lucro líquido do } \\
\text { exercício/patrimônio líquido }\end{array}$ \\
\hline
\end{tabular}

Figura 4. Relação dos indicadores e variáveis econômicas

Fonte: Adaptado de Gitman (2010) e Chiavenato (2014).

A Figura 4 apresenta os indicadores operacionais, com o propósito de analisar as variações ocorridas nas variáveis de produção dos setores. A Figura 5 evidencia os indicadores econômicos analisados, a fim de verificar os reflexos na estrutura e vertentes econômicas das empresas do setor elétrico. Já a Figura 6 mostra os indicadores GRI, propondo-se uma análise da perspectiva do desempenho econômico e de suplemento setorial das empresas. 
Os reflexos da crise hídrica brasileira na estrutura de custos das empresas do setor de energia elétrica

Ângelo Wesley de Sousa Falcão, Rosângela Venâncio Nunes, Charles Washington Costa de Assis, Nayana de Almeida Adriano, Alexandra Alencar Siebra

\begin{tabular}{|c|c|}
\hline INDICADORES OPERACIONAIS & DESCRIÇÃo \\
\hline $\begin{array}{c}\text { PRODUÇÃO/COMERCIALIZAÇÃO/ } \\
\text { DISTRIBUIÇÃO DE ENERGIA }\end{array}$ & $\begin{array}{r}\text { Corresponde ao total de energia produzida, comercializada } \\
\text { ou distribuída pela empresa no período }\end{array}$ \\
\hline GARANTIA FÍSICA & $\begin{array}{c}\text { Corresponde à quantidade máxima de energia que pode ser } \\
\text { comercializada por meio de contratos. }\end{array}$ \\
\hline PREÇO MÉDIO GERAL - R\$ & $\begin{array}{c}\text { Corresponde ao preço total de venda da energia (em reais) em } \\
\text { relação à quantidade total de venda de energia (em MWh). }\end{array}$ \\
\hline CLASSIFICAÇÃO RATING & $\begin{array}{c}\text { Corresponde a uma previsão ou um indicador de potencial de } \\
\text { perda de crédito devido ao não pagamento, atraso ou } \\
\text { pagamento parcial aos investidores, classificando as empresas } \\
\text { em "Grau de Investimento" ou "Grau Especulativo". }\end{array}$ \\
\hline
\end{tabular}

Figura 5. Relação dos indicadores e variáveis operacionais

Fonte: Elaborado pelos autores (2016) com base nos relatórios anuais analisados.

\begin{tabular}{|c|c|}
\hline \multicolumn{2}{|c|}{$\begin{array}{l}\text { INDICADORES GLOBAL REPORTING INITIATIVE - GRI } \\
\end{array}$} \\
\hline $\begin{array}{l}\text { GRUPO DESEMPENHO } \\
\text { ECONÔMICO }\end{array}$ & DESCRIÇÃO \\
\hline GRI EC1 & Corresponde ao valor econômico direto gerado e distribuído \\
\hline GRI EC2 & $\begin{array}{l}\text { Corresponde às implicações financeiras, riscos e oportunidades } \\
\text { de mudanças climáticas }\end{array}$ \\
\hline $\begin{array}{l}\text { GRUPO SUPLEMENTO SETORIAL - } \\
\text { SETOR ELÉTRICO }\end{array}$ & DESCRIÇÃO \\
\hline GRI EU1 & $\begin{array}{c}\text { Corresponde à capacidade instalada, discriminada por fonte de } \\
\text { energia primária e por sistema regulatório }\end{array}$ \\
\hline GRI EU2 & $\begin{array}{l}\text { Corresponde ao número de unidades consumidoras residenciais, } \\
\text { industriais, institucionais e comerciais }\end{array}$ \\
\hline
\end{tabular}

Figura 6. Relação dos indicadores e variáveis

Fonte: Adaptado de GRI (2015).

Ressalta-se que a aplicação de alguns indicadores operacionais e GRI não se torna viável, permanecendo no estudo a análise da classificação rating e da capacidade instalada (GRI EU1). 
Os reflexos da crise hídrica brasileira na estrutura de custos das empresas do setor de energia elétrica

Ângelo Wesley de Sousa Falcão, Rosângela Venâncio Nunes, Charles Washington Costa de Assis, Nayana de Almeida Adriano, Alexandra Alencar Siebra

Para uma melhor apresentação e visualização dos resultados obtidos com a análise, foram elaborados gráficos e tabelas, utilizando-se as variações percentuais e as médias aritméticas acumuladas dos setores, em cada ano analisado, para o grupo de empresas da cadeia produtiva. A análise por percentuais se faz necessária para que seja possível manter a comparabilidade entre as empresas, tendo em vista que a amostra possui empresas de diferentes portes.

Após a obtenção dos percentuais antes e depois da crise hídrica, procedeu-se à identificação dos reflexos da crise em "favoráveis" e "desfavoráveis". A situação "favorável" é qualificada quando os custos e despesas apresentarem variações para menos e quando as demais variáveis e indicadores apresentarem variações para mais, com base na comparação entre os períodos. Já a situação "desfavorável" é qualificada quando ocorre o inverso, com os custos e despesas variando para mais e as demais variáveis e indicadores variando para menos, quando analisados comparativamente os períodos.

\section{APRESENTAÇÃo E ANÁLISE DOS RESULTADOS}

Esta seção objetiva analisar as mudanças ocorridas nas variáveis das empresas de geração, transmissão e distribuição de energia e do consumidor final nos anos de 2011 a 2015. A análise está voltada para a verificação de variações percentuais dos indicadores e variáveis por média dos anos e em dois períodos antes da crise (20112013) e durante a crise (2013 a 2015), a fim de evidenciar se as mudanças ocorridas foram favoráveis ou desfavoráveis para os segmentos da cadeia (geração/transmissão/distribuição e consumidor final). 
Os reflexos da crise hídrica brasileira na estrutura de custos das empresas do setor de energia elétrica

Ângelo Wesley de Sousa Falcão, Rosângela Venâncio Nunes, Charles Washington Costa de Assis, Nayana de Almeida Adriano, Alexandra Alencar Siebra

\subsection{Reflexos da Crise Hídrica nos indicadores e variáveis analisadas na cadeia produtiva}

Para analisar os reflexos na cadeia produtiva, foram utilizadas as variáveis e indicadores econômicos e GRI EC1, a fim de garantir comparabilidade entre as cadeias, já que estes dois grupos de indicadores foram evidenciados em todas as empresas analisadas.

A seguir, a Figura 7 apresenta os reflexos dos indicadores e variáveis econômicas por cada setor da cadeia produtiva. 
Os reflexos da crise hídrica brasileira na estrutura de custos das empresas do setor de energia elétrica Ângelo Wesley de Sousa Falcão, Rosângela Venâncio Nunes, Charles Washington Costa de Assis, Nayana de Almeida Adriano, Alexandra Alencar Siebra

\begin{tabular}{|c|c|c|c|c|c|c|c|c|c|c|c|c|}
\hline $\begin{array}{l}\text { S } \\
\text { E } \\
\mathbf{T} \\
\mathbf{O} \\
\mathbf{R}\end{array}$ & $\begin{array}{c}\text { COMPORTAMENTO } \\
\text { VERICADO }\end{array}$ & $\frac{\mathbb{5}}{8} \frac{\overline{2}}{8}$ & $\begin{array}{l}\frac{g}{8} \frac{\pi}{3} \\
\frac{8}{3}\end{array}$ & $\begin{array}{l}88 \\
8 \frac{8}{7} \\
08 \\
0\end{array}$ & $\begin{array}{l}8 \\
8 \\
8 \\
8 \\
8 \\
8\end{array}$ & $\begin{array}{l}\frac{0}{2} \\
\frac{8}{8} \\
\frac{8}{8} \\
\frac{8}{8}\end{array}$ & 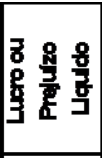 & $\begin{array}{l}\mathbf{3} \\
\mathbf{8} \\
\mathbf{8} \\
\mathbf{3}\end{array}$ & 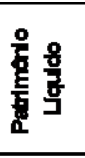 & $\frac{\mathbb{E}}{\mathbb{1}}$ & $\bar{Z}$ & 岩 \\
\hline \multirow{2}{*}{$\begin{array}{l}\mathbf{G} \\
\mathbf{E} \\
\mathbf{R} \\
\mathbf{A} \\
\mathbf{C} \\
\overrightarrow{\mathbf{A}} \\
\mathbf{O}\end{array}$} & $\begin{array}{l}\text { VARIAçĀO MÉDIA } \\
\text { ACUMULADA } 2011 \text { A } 2015 \\
\text { MÉDIA DE VARIAÇĀo } \\
\text { ANTES DA CRISE } \\
\text { MÉDIA DE VARIAÇĀo } \\
\text { DURAN TE A CRISE }\end{array}$ & $\begin{array}{l}6 \% \\
10 \% \\
1 \%\end{array}$ & $\begin{array}{r}5 \% \\
11 \% \\
-1 \% \\
\end{array}$ & $\begin{array}{l}75 \% \\
117 \% \\
33 \% \\
\end{array}$ & $\begin{array}{l}0 \% \\
2 \% \\
-1 \% \\
\end{array}$ & $\begin{array}{l}23 \% \\
37 \% \\
8 \%\end{array}$ & \begin{tabular}{r|}
$14 \%$ \\
$-35 \%$ \\
$7 \%$ \\
\end{tabular} & $\begin{array}{l}14 \% \\
-2 \% \\
31 \% \\
\end{array}$ & \begin{tabular}{r|}
$-9 \%$ \\
$-25 \%$ \\
$8 \%$
\end{tabular} & $\begin{array}{r}-15 \% \\
-21 \% \\
-9 \%\end{array}$ & $\begin{array}{r}-16 \% \\
-34 \% \\
3 \%\end{array}$ & $\begin{array}{r}-29 \% \\
-53 \% \\
-4 \%\end{array}$ \\
\hline & REFLEXOS DA CRISE & 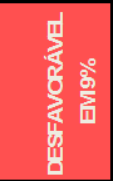 & 㟶 & 㝏 & 而 & 宜 & 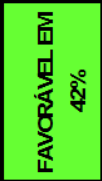 & 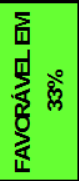 & 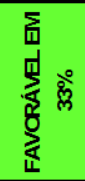 & 目 & 宣 & 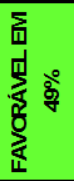 \\
\hline \multirow{2}{*}{$\begin{array}{l}\mathbf{T} \\
\mathbf{R} \\
\mathbf{A} \\
\mathbf{N} \\
\mathbf{S} \\
\mathbf{M} \\
\mathbf{I} \\
\mathbf{S} \\
\mathbf{S} \\
\mathbf{A} \\
\mathbf{O}\end{array}$} & $\begin{array}{l}\text { VARIAÇĀO MÉDIA } \\
\text { ACUMULADA } 2011 \text { A } 2015 \\
\text { MÉDIA DE VARIAÇĀO } \\
\text { ANTES DA CRISE } \\
\text { MÉDIA DE VARIAÇĀO } \\
\text { DURAN TE A CRISE }\end{array}$ & $-3 \%$ & $\begin{array}{l}0 \% \\
-1 \% \\
2 \% \\
\end{array}$ & $\begin{array}{l}60 \% \\
75 \% \\
45 \% \\
\end{array}$ & $\begin{array}{r}1 \% \\
11 \% \\
-9 \% \\
\end{array}$ & $\begin{array}{l}27 \% \\
41 \% \\
13 \% \\
\end{array}$ & $\begin{array}{r}87 \% \\
-7 \% \\
182 \% \\
\end{array}$ & $\begin{array}{l}3 \% \\
5 \% \\
1 \% \\
\end{array}$ & $\begin{array}{l}9 \% \\
15 \% \\
2 \% \\
\end{array}$ & \begin{tabular}{l|}
$1 \%$ \\
$-5 \%$ \\
$7 \%$ \\
\end{tabular} & \begin{tabular}{r|}
$82 \%$ \\
$-12 \%$ \\
$177 \%$ \\
\end{tabular} & \begin{tabular}{r|}
$76 \%$ \\
$18 \%$ \\
$171 \%$ \\
\end{tabular} \\
\hline & REFLEXOS DA CRISE & 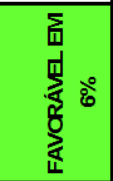 & 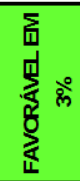 & 宜 & 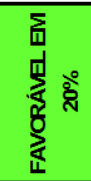 & 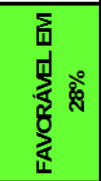 & 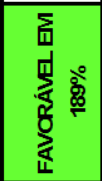 & 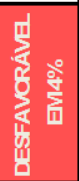 & 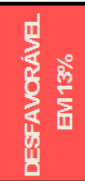 & 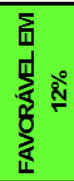 & 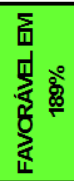 & 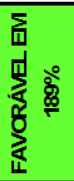 \\
\hline \multirow{2}{*}{$\begin{array}{l}\mathbf{D} \\
\mathbf{I} \\
\mathbf{S} \\
\mathbf{T} \\
\mathbf{R} \\
\mathbf{I} \\
\mathbf{B} \\
\mathbf{U} \\
\mathbf{I} \\
\mathbf{C} \\
\mathbf{A} \\
\mathbf{O}\end{array}$} & $\begin{array}{l}\text { VARIAÇĀO MÉDIA } \\
\text { ACUMULADA } 2011 \text { A } 2015 \\
\text { MÉDIA DE VARIAÇĀO } \\
\text { ANTES DA CRISE } \\
\text { MÉDIA DE VARIAÇĀO } \\
\text { DURAN TE A CRISE }\end{array}$ & $\begin{array}{l}16 \% \\
-1 \% \\
33 \%\end{array}$ & $\begin{array}{l}12 \% \\
3 \% \\
21 \%\end{array}$ & $\begin{array}{l}60 \% \\
75 \% \\
45 \%\end{array}$ & $\begin{array}{l}20 \% \\
10 \% \\
-9 \%\end{array}$ & $\begin{array}{l}6 \% \\
4 \% \\
9 \%\end{array}$ & $\begin{array}{c}31 \% \\
-6 \% \\
68 \%\end{array}$ & $\begin{array}{l}43 \% \\
21 \% \\
66 \%\end{array}$ & $\begin{array}{l}9 \% \\
5 \% \\
13 \%\end{array}$ & $\begin{array}{r}-26 \% \\
-1 \% \\
-50 \%\end{array}$ & $\begin{array}{l}32 \% \\
15 \% \\
48 \%\end{array}$ & $\begin{array}{l}4 \% \\
12 \% \\
-5 \%\end{array}$ \\
\hline & REFLEXOS DA CRISE & 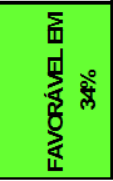 & 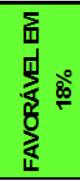 & 面 & 而 & 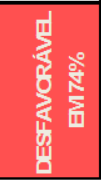 & 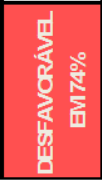 & 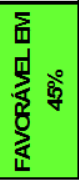 & 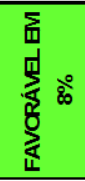 & 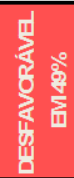 & 皿 & 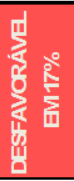 \\
\hline
\end{tabular}

Figura 7. Reflexos dos indicadores e variáveis econômicas da cadeia produtiva

Fonte: Elaborada pelos autores, com base nas informações coletadas dos relatórios anuais.

Por meio da Figura 7, observa-se, com relação aos reflexos, pode-se destacar a situação favorável do custo do serviço em energia, que, com a crise, foi reduzido de uma variação de $117 \%$ para 33\%, tornando-se favorável em $84 \%$. Verifica-se que, apesar das receitas operacionais e líquidas se apresentarem como desfavoráveis (em $9 \%$ e 12\%, respectivamente), a crise foi, em média geral, favorável para o setor. Isso não evidencia que, por exemplo, os custos, por apresentarem situação favorável, 
Os reflexos da crise hídrica brasileira na estrutura de custos das empresas do setor de energia elétrica

Ângelo Wesley de Sousa Falcão, Rosângela Venâncio Nunes, Charles Washington Costa de Assis, Nayana de Almeida Adriano, Alexandra Alencar Siebra

tenham sido de fato menores, mas sim que as empresas administraram essas variáveis para que não houvesse elevações significativas e prejudiciais à estrutura econômica.

Analisando a Figura 7 juntamente com a Figura 8 , é possível verificar as alterações na estrutura de custos a partir das alterações operacionais.Com base na variação média do setor, constata-se que, apesar do decréscimo na produção de energia $(-1 \%)$, a receita operacional aumentou $(6 \%)$, devido à elevação do preço médio geral de venda de energia em $11 \%$ e ao aumento dos clientes ativos em $8 \%$.Contudo, o lucro líquido variou negativamente em $-14 \%$, consequência, principalmente, da baixa variação da receita em $6 \%$, do aumento considerável do custo do serviço em energia elétrica em $75 \%$ e das despesas operacionais em $23 \%$, o que também acarretou a variação média negativa do EBITDA em -15\%.

Apesar de o ativo total apresentar variação média positiva de $14 \%$, o ROI se apresentou de forma negativa, devido à variação média negativa do lucro líquido. Já o ROE, que apresentou variação média de $-29 \%$, é consequência clara das variações negativas do lucro líquido e do patrimônio líquido (-9\%). As variações médias na garantia física e na capacidade instalada não produziram impactos relevantes, variando em $0 \%$ e $-2 \%$, respectivamente.

A Figura 7 evidencia ainda que, com relação aos reflexos da crise, é possível verificar que os indicadores econômicos do setor de transmissão apresentaram variações favoráveis em sua grande maioria, se comparadas às variações antes da crise e durante a crise, com destaque para o custo do serviço, tornando-se favorável em $30 \%$ com a crise, havendo redução da média de $75 \%$ antes da crise para $45 \%$ depois da crise.

Assim, o setor de transmissão, de forma semelhante ao setor de geração, apresentou reflexos econômicos médios gerais favoráveis com a crise, com destaque para o lucro líquido do período, que apresentou variação média favorável em 189\% quando comparado ao período anterior à crise. 
Os reflexos da crise hídrica brasileira na estrutura de custos das empresas do setor de energia elétrica

Ângelo Wesley de Sousa Falcão, Rosângela Venâncio Nunes, Charles Washington Costa de Assis, Nayana de Almeida Adriano, Alexandra Alencar Siebra

Ao se observar a Figura 7, podem-se destacar as elevadas variações positivas da receita operacional do setor de distribuição, principalmente na variação 2014-2015, o que produziu uma variação média do segmento de $16 \%$. De acordo com os relatórios anuais analisados, essas variações se devem, em suma, pelo reajuste das tarifas de comercialização de energia elétrica. Outro ponto a ser destacado é o aumento constante do custo com energia elétrica, influenciado pelas variações também positivas da cadeia, que gerou uma variação média geral de $20 \%$ no setor. $\mathrm{Na}$ análise dos reflexos da crise, observa-se que a quantidade de indicadores econômicos que variaram favoravelmente com a crise foi, em média, semelhante à quantidade desfavorável, com destaque para a receita bruta (favorável em $34 \%$ ) e para os custos com energia e despesas operacionais (desfavoráveis em $20 \%$ e $74 \%$, respectivamente). Além disso, pela primeira vez, os custos e despesas se mostraram desfavoráveis com a crise, apresentando reflexos desfavoráveis nos percentuais de $20 \%, 5 \%$ e $74 \%$.

Para o setor de distribuição, pode-se considerar que os reflexos da crise foram balanceados, tendo em vista que houve variações, em média, favoráveis na mesma proporção de variações desfavoráveis. Como resultado da elevação do preço médio ao consumidor final, explanado anteriormente, tem-se uma variação favorável da receita bruta em $34 \%$, o que, apesar da variação desfavorável do custo com energia, em $20 \%$, e das despesas operacionais, em $74 \%$, conseguiu-se obter uma variação do lucro líquido favorável em $45 \%$. A Figura 8 , a seguir, apresenta as variações dos indicadores operacionais e de suplemento setorial (GRI EU1 e GRI EU3) do setor de geração. 
Os reflexos da crise hídrica brasileira na estrutura de custos das empresas do setor de energia elétrica

Ângelo Wesley de Sousa Falcão, Rosângela Venâncio Nunes, Charles Washington Costa de Assis, Nayana de Almeida Adriano, Alexandra Alencar Siebra

\begin{tabular}{|c|c|c|c|c|c|}
\hline \multirow[b]{2}{*}{ COUPORTAUENTO VERICADO } & \multicolumn{3}{|c|}{ OPERACIONAIS } & \multicolumn{2}{|c|}{ SETORIALS } \\
\hline & $\begin{array}{l}\text { Proudgaroue } \\
\text { Energia (em } \\
\text { GWh) }\end{array}$ & $\begin{array}{l}\text { Garantia Fisica } \\
\text { (em UW) }\end{array}$ & $\begin{array}{l}\text { Preço Wédio } \\
\text { (RșUWh) }\end{array}$ & $\begin{array}{l}\text { GKIEUT } \\
\text { (Capacidade } \\
\text { Instalada) }\end{array}$ & $\begin{array}{c}\text { GRIEUS } \\
\text { (Quantidade de } \\
\text { Clientes) }\end{array}$ \\
\hline VARIAÇÄO UÉDIA ACUUULADA 2011 A 2015 & $1 \%$ & $0 \%$ & $11 \%$ & $-2 \%$ & $8 \%$ \\
\hline UÉDIA DE V ARIAÇÃO ANTES DA CRISE & $0 \%$ & $-1 \%$ & $10 \%$ & $-1 \%$ & $11 \%$ \\
\hline UÉDIA DE V ARIAÇÃO DURANTE A CRISE & $-3 \%$ & $0 \%$ & $12 \%$ & $-3 \%$ & $4 \%$ \\
\hline REFLEXOS DA CRISE & $\begin{array}{l}\text { DESFAVORÁVEL } \\
\text { EM } 3 \%\end{array}$ & $\begin{array}{l}\text { FAVORÁVEL EM } \\
1 \%\end{array}$ & $\begin{array}{c}\text { FAVORÁV EL EM } \\
2 \%\end{array}$ & $\begin{array}{l}\text { DESFAV ORÁVEL } \\
\text { EM } 2 \%\end{array}$ & $\begin{array}{l}\text { DESFAV ORÁVEL } \\
\text { EM } 9 \%\end{array}$ \\
\hline
\end{tabular}

Figura 8. Variáveis e indicadores operacionais e de suplemento setorial do setor geração

Fonte: Elaborada pelos autores, com base nas informações coletadas dos relatórios anuais.

Em relação aos reflexos operacionais, é possível verificar que a crise foi desfavorável, em média, para o setor de geração de energia.

Quanto aos riscos e oportunidades de mudanças climáticas (indicador GRI EC2), o risco hídrico foi citado por, praticamente, todas as empresas em seus relatórios, enfatizando as condições hidrológicas desfavoráveis à geração de energia hidrelétrica durante os anos em estudo. Como oportunidade, grande parte dos relatórios citou 0 desenvolvimento de novos projetos de geração com a finalidade de garantir 0 atendimento à demanda de energia com uma menor dependência do regime hidrológico.

Em relação à classificação rating, as empresas foram avaliadas pelas agências Fitch Ratings (Fitch), Moody's e/ou Standard \& Poor's (S\&P) e classificadas, de forma geral ao longo dos anos, em grau de investimento (investment grade), indicando probabilidade baixa a moderada de inadimplência. Isso mostra que, mesmo diante de situações de risco hídrico, as empresas conseguiram gerenciar seus recursos para cumprir as obrigações com os stakeholders.

Conclui-se, a partir da análise das empresas geradoras, que as variáveis econômicas apresentam situação essencialmente favorável com a crise, enquanto que, em média, as variáveis operacionais apresentaram situação desfavorável. 
Os reflexos da crise hídrica brasileira na estrutura de custos das empresas do setor de energia elétrica

Ângelo Wesley de Sousa Falcão, Rosângela Venâncio Nunes, Charles Washington Costa de Assis, Nayana de Almeida Adriano, Alexandra Alencar Siebra

O estudo verificou que não houve variações significativas na capacidade instalada dessas empresas do setor de transmissão ao longo dos anos, onde somente a CTEEP apresentou uma variação média favorável de $6 \%$.

Ainda sobre o setor de transmissão, em relação ao indicador GRI EC2 (implicações financeiras, riscos e oportunidades de mudanças climáticas), não foram localizadas referências a este indicador em nenhum dos relatórios anuais analisados.

Quanto à classificação rating, as empresas CTEEP e TAESA apresentaram classificações de grau de investimento ao longo do período em análise, avaliadas pelas agências Fitch Ratings, Moody's e Standard \& Poor's. Com relação à empresa AFLUENTE T, não foram localizadas classificações dessa natureza em seus relatórios anuais.

Pode-se concluir, a partir da análise do setor de transmissão de energia elétrica que, tanto as variáveis econômicas quanto as operacionais, apresentaram reflexos favoráveis na estrutura das empresas pertencentes a este setor.

A Figura 9, a seguir, evidencia as variações nos indicadores e variáveis operacionais e setoriais das empresas brasileiras do setor de distribuição.

\begin{tabular}{|c|c|c|c|c|}
\hline \multirow[b]{2}{*}{ COMPORTAMENTO VERICADO } & \multicolumn{2}{|c|}{ OPERACIONAIS } & \multicolumn{2}{|c|}{ SETORIAIS } \\
\hline & $\begin{array}{l}\text { UTsinbuçao de } \\
\text { Energia (em } \\
\text { GWh) }\end{array}$ & $\begin{array}{l}\text { Preço Médio } \\
\text { (R\$/MWh) }\end{array}$ & $\begin{array}{l}\text { GRTEUT } \\
\text { (Capacidade } \\
\text { Instalada) }\end{array}$ & $\begin{array}{c}\text { GRIEU3 } \\
\text { (Quantidade de } \\
\text { Clientes) }\end{array}$ \\
\hline VARIAÇĀO MÉDIA ACUMULADA 2011 A 2015 & $2 \%$ & $13 \%$ & $3 \%$ & $3 \%$ \\
\hline MÉDIA DE VARIAÇĀO ANTES DA CRISE & 4\% & $-5 \%$ & 3\% & $3 \%$ \\
\hline MÉDIA DE VARIAÇĀO DURANTE A CRISE & $1 \%$ & $31 \%$ & $4 \%$ & $2 \%$ \\
\hline REFLEXOS DA CRISE & $\begin{array}{l}\text { DESFAVORAVEL } \\
\text { EM } 3 \%\end{array}$ & $\begin{array}{l}\text { FAVORAVEL EMT } \\
36 \%\end{array}$ & $\begin{array}{l}\text { FAVORAVEL EM } \\
1 \%\end{array}$ & $\begin{array}{l}\text { DESFAVORAVEL } \\
\text { EM } 9 \%\end{array}$ \\
\hline
\end{tabular}

Figura 9. Variáveis e indicadores operacionais e setoriais do setor distribuição

Fonte: Elaborada pelos autores, com base nas informações coletadas dos relatórios anuais.

Em uma análise conjunta das variações médias acumuladas presentes nas Figuras 7 e 9, pode-se verificar que, apesar da variação de a distribuição de energia ser 
Os reflexos da crise hídrica brasileira na estrutura de custos das empresas do setor de energia elétrica

Ângelo Wesley de Sousa Falcão, Rosângela Venâncio Nunes, Charles Washington Costa de Assis, Nayana de Almeida Adriano, Alexandra Alencar Siebra

de apenas $2 \%$, a receita operacional variou na ordem de $16 \%$, devido à elevação média do preço geral praticado em $13 \%$ e da quantidade de clientes em $3 \%$. Como resultado de uma variação positiva do lucro líquido em $43 \%$ e do ativo em $9 \%$, tem-se o $\mathrm{ROI}$ em $32 \%$. Já o ROE apresentou baixa variação (4\%), devido à variação média negativa do patrimônio líquido em -26\%. A variação média negativa do EBITDA em $-11 \%$ resulta das variações positivas do custo com energia em $20 \%$, do custo com operação em $6 \%$ e das despesas operacionais em $31 \%$.

$\mathrm{Na}$ análise dos reflexos da crise, pode-se considerar que as mudanças foram favoráveis, pois, apesar de alguns indicadores apresentarem variações desfavoráveis, a relevância da variação do preço médio geral na estrutura de custos (favorável em 36\%) superou os reflexos ruins.

Com relação ao indicador GRI EC2, grande parte dos relatórios analisados das empresas pertencentes ao setor de distribuição que evidenciaram este indicador citaram como risco a possibilidade de interrupções no fornecimento de energia decorrente de dificuldades na geração de energia elétrica de fonte hidrelétrica (agravada pela escassez no volume de chuvas). Como oportunidade, foram citados, em suma, os investimentos para robustez da rede de distribuição, a fim de elevar a qualidade do serviço, além dos altos investimentos na geração de energia a partir de fontes renováveis, a fim de garantir a segurança energética do país.

As empresas em estudo foram analisadas e classificadas pelas agências Fitch Ratings, Moody's e Standard \& Poor's, e apresentaram rating de grau de investimento (investment grade). No ano de 2015, as empresas COELBA, CELPE e COSERN foram rebaixadas de perspectiva estável para perspectiva negativa, a qual, de acordo com os relatórios anuais, é consequência do rebaixamento do rating soberano do Brasil.

Conclui-se com a análise que a crise hídrica acarretou reflexos balanceados na estrutura de custos das empresas distribuidoras, com variações, em média, favoráveis para as receitas e desfavoráveis para os custos e despesas do período, e favoráveis 
Os reflexos da crise hídrica brasileira na estrutura de custos das empresas do setor de energia elétrica

Ângelo Wesley de Sousa Falcão, Rosângela Venâncio Nunes, Charles Washington Costa de Assis, Nayana de Almeida Adriano, Alexandra Alencar Siebra

para a atividade operacional, mediante as elevações do preço médio de comercialização de energia.

$\mathrm{Na}$ Figura 10 a seguir, são apresentados os gráficos das variações de valor gerado e valor distribuído por setor e da cadeia produtiva como um todo do setor elétrico brasileiro.

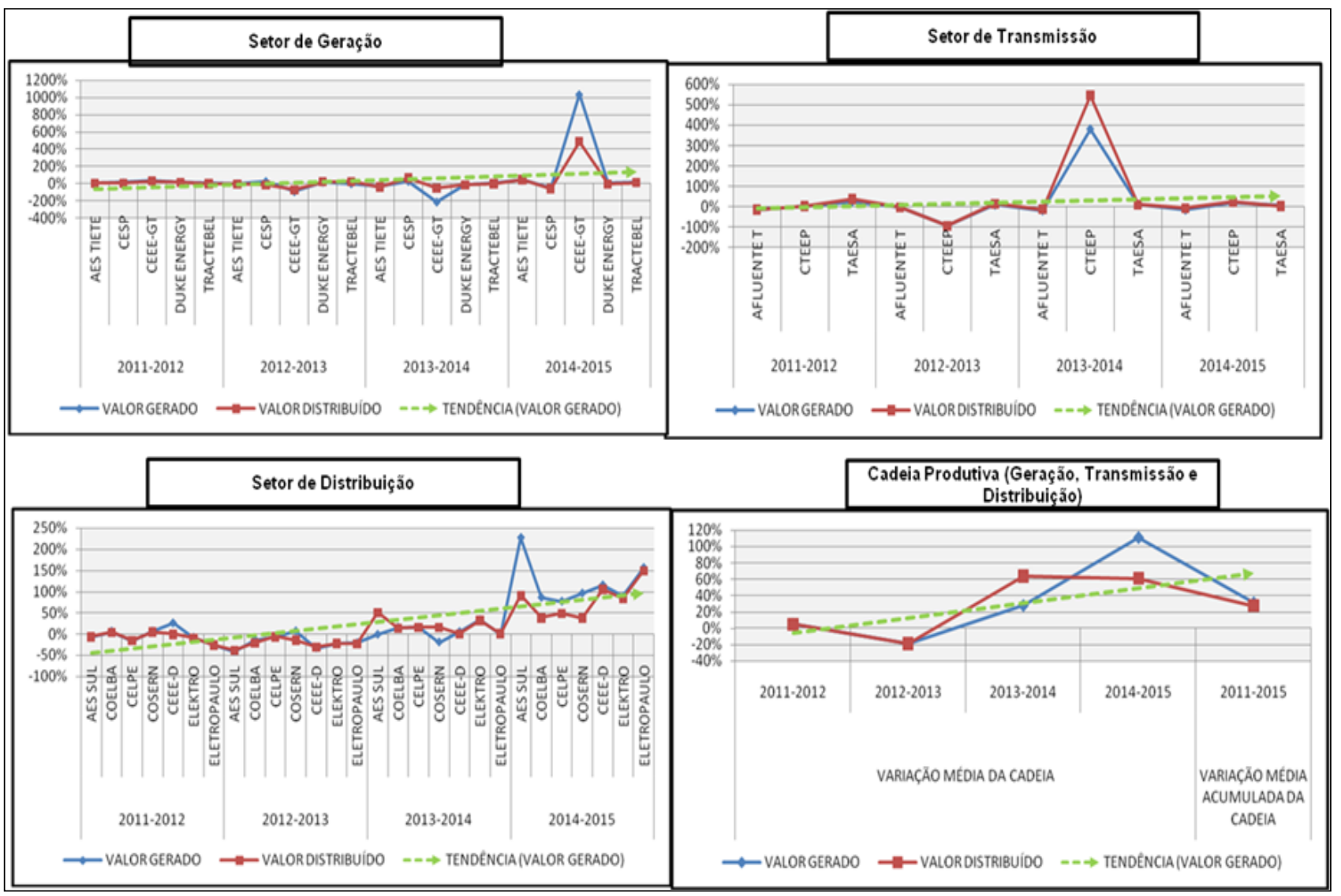

Figura 10. Gráficos do Valor gerado e valor distribuído da cadeia produtiva do setor elétrico Fonte: Elaborada pelos autores, com base nas informações coletadas dos relatórios anuais.

Na Figura 10, é visível que, ao longo dos anos, no setor de geração, o valor distribuído variou, de forma idêntica, ao valor gerado pelas empresas (linhas cores vermelha e azul), com maior destaque para a empresa CEEE-GT no período 2014- 
Os reflexos da crise hídrica brasileira na estrutura de custos das empresas do setor de energia elétrica

Ângelo Wesley de Sousa Falcão, Rosângela Venâncio Nunes, Charles Washington Costa de Assis, Nayana de Almeida Adriano, Alexandra Alencar Siebra

2015, em que a variação do valor distribuído foi menor que a variação do valor gerado. Analisando-se a linha de tendência (cor verde), é possível verificar que, na variação média, o valor gerado apresentou tendência de evolução no período em análise.

No que se refere às transmissoras pode-se verificar similaridade nas variações ao longo do período, com destaque para a variação do valor distribuído acima da variação do valor gerado na empresa CTEEP em 2013-2014. A linha de tendência evidencia que houve evolução do valor gerado no setor de transmissão no decorrer do período.

No setor de distribuição, verifica-se, em média, que as variações do valor distribuído foram similares às variações do valor gerado. Na comparação 2014-2015, as duas variáveis apresentaram elevações consideráveis em todas as empresas analisadas, consequência, principalmente, do aumento da receita operacional. A linha de tendência evidencia que, de forma semelhante aos setores de geração e distribuição, houve média de evolução no valor gerado.

Como se verifica na Figura 10, a cadeia produtiva gerou valor de forma similar nos anos 2012 e 2013. No ano de 2014, em comparação a 2013, a variação do valor distribuído foi maior que do valor gerado, diferente do ano de 2015, onde aconteceu a situação inversa. Analisando-se a variação acumulada da cadeia, percebe-se que houve uma variação média semelhante das duas variáveis. A linha de tendência expressa que houve evolução média do valor gerado no período analisado.

Com a análise da cadeia produtiva do setor elétrico, pode-se concluir que a crise hídrica produziu, em média, reflexos econômicos favoráveis para o setor de geração e transmissão de energia e reflexos balanceados para o setor de distribuição de energia elétrica. 
Os reflexos da crise hídrica brasileira na estrutura de custos das empresas do setor de energia elétrica

Ângelo Wesley de Sousa Falcão, Rosângela Venâncio Nunes, Charles Washington Costa de Assis, Nayana de Almeida Adriano, Alexandra Alencar Siebra

\subsection{Reflexos da Crise Hídrica nas variáveis do consumidor por modalidade de clientes}

Para a análise dos reflexos para o consumidor final, foram considerados os preços e as quantidades de energia elétrica comercializada pelas distribuidoras AES Sul, COELBA, CELPE, COSERN, CEEE-D, ELEKTRO e ELETROPAULO, e as modalidades de venda "residencial", "industrial", "comercial", "rural", "poder público", "iluminação pública" e "serviço público", como apresentado a seguir.

A Figura 11, a seguir, apresenta as variações médias gerais de vendas das sete empresas em reais e em megawattshora, segregados por modalidade consumidora no mercado cativo.

\begin{tabular}{|c|c|c|c|c|c|c|c|c|}
\hline & \multicolumn{8}{|c|}{ MODALDADE CONSUMIDORA } \\
\hline & CONPORTALENTO & RESIDENCLAL & NDUSTRAAL & COMERCAL & RARAL & PODER PÚBUICO & $\begin{array}{l}\text { LUNTAÇĀO } \\
\text { PÚBuCA }\end{array}$ & $\begin{array}{l}\text { SERVIÇO } \\
\text { PÚ́EYCO }\end{array}$ \\
\hline $\begin{array}{l}\text { VARAAÇÃO LÉDAA ANIES } \\
\text { DA CRASE }\end{array}$ & \begin{tabular}{|l} 
Vendas (em Rt) \\
Vendas (em MWh)
\end{tabular} & $\begin{array}{l}0 \% \\
6 \%\end{array}$ & $\begin{array}{l}-13 \% \\
-10 \%\end{array}$ & $\begin{array}{r}-2 \% \\
5 \%\end{array}$ & $\begin{array}{l}3 \% \\
7 \%\end{array}$ & $\begin{array}{r}-2 \% \\
4 \%\end{array}$ & $\begin{array}{r}-3 \% \\
2 \%\end{array}$ & $\begin{array}{r}-5 \% \\
4 \%\end{array}$ \\
\hline $\begin{array}{l}\text { VARAACĀO MÉDAA } \\
\text { DURANTE A CRISE }\end{array}$ & \begin{tabular}{|l} 
Vendas (em Rq) \\
Vendas (em MWh)
\end{tabular} & $\begin{array}{r}38 \% \\
2 \% \\
\end{array}$ & $\begin{array}{r}32 \% \\
-4 \% \\
\end{array}$ & $\begin{array}{r}39 \% \\
4 \% \\
\end{array}$ & $\begin{array}{r}37 \% \\
1 \% \\
\end{array}$ & $\begin{array}{r}35 \% \\
1 \% \\
\end{array}$ & $\begin{array}{r}35 \% \\
2 \% \\
\end{array}$ & $\begin{array}{l}24 x \\
-4 x \\
\end{array}$ \\
\hline \multirow{2}{*}{ REPLEXOS DA CRISE } & Vendas (em R\$) & \begin{tabular}{|c|} 
FAVORÁVEL EM \\
$38 \%$
\end{tabular} & $\begin{array}{c}\text { FAVORÁVEL EM } \\
38 \%\end{array}$ & $\begin{array}{c}\text { FAVORÁVEL EM } \\
38 \%\end{array}$ & $\begin{array}{c}\text { FAVORÁVEL EM } \\
38 \%\end{array}$ & $\begin{array}{c}\text { FAVORÁVEL EM } \\
38 \%\end{array}$ & $\begin{array}{c}\text { FAVORÁVEL EM } \\
38 \%\end{array}$ & $\begin{array}{c}\text { FAVORÁVEL EM } \\
38 \%\end{array}$ \\
\hline & Vendas ( $\mathrm{em}$ MWh) & $\left|\begin{array}{c}\text { DESFAVORÁVEL } \\
\text { EM 4\% }\end{array}\right|$ & $\begin{array}{c}\text { FAVORÁVEL EM } \\
38 \%\end{array}$ & $\begin{array}{c}\text { DESFAVORÁVEL } \\
\text { EM } 4 \%\end{array}$ & $\begin{array}{c}\text { DESFAVORÁVEL } \\
\text { EM 4\% }\end{array}$ & $\begin{array}{l}\text { DESFAVORÁVEL } \\
\text { EM 4\% }\end{array}$ & $\begin{array}{l}\text { SEMRPLEXos } \\
\text { REFVANIES }\end{array}$ & $\begin{array}{c}\text { DESFAVORÁVEL } \\
\text { EM } 4 \%\end{array}$ \\
\hline
\end{tabular}

Figura 11. Variações médias das vendas de energia no mercado cativo - em R\$ e MWh Fonte: Elaborada pelos autores, com base nas informações coletadas dos relatórios anuais.

Conforme se pode verificar na Figura 11, a quantidade total de megawattshora vendida aos consumidores variou muito abaixo em comparação ao total das vendas em reais, principalmente nas comparações 2013-2014 e 2014-2015. Isso evidencia que houve um aumento bastante elevado no preço médio de venda de energia elétrica aos consumidores do mercado cativo, acarretado, principalmente, pelos reajustes do governo nas tarifas de comercialização de energia, de acordo com o exposto nos relatórios analisados. 
Os reflexos da crise hídrica brasileira na estrutura de custos das empresas do setor de energia elétrica

Ângelo Wesley de Sousa Falcão, Rosângela Venâncio Nunes, Charles Washington Costa de Assis, Nayana de Almeida Adriano, Alexandra Alencar Siebra

A elevação do preço médio para o consumidor do mercado cativo fica evidente quando se analisam os reflexos da crise, em que é possível verificar que as vendas em reais variaram em altas favoráveis, enquanto que as vendas em MWh variaram desfavoravelmente. Com base nisso, pode-se destacar a modalidade residencial, que passou de variações médias favoráveis, no período anterior, à crise (38\%) para variações desfavoráveis durante a crise (4\%).

A Figura 12 apresenta as variações do preço médio de comercialização de energia no mercado cativo, por empresa.

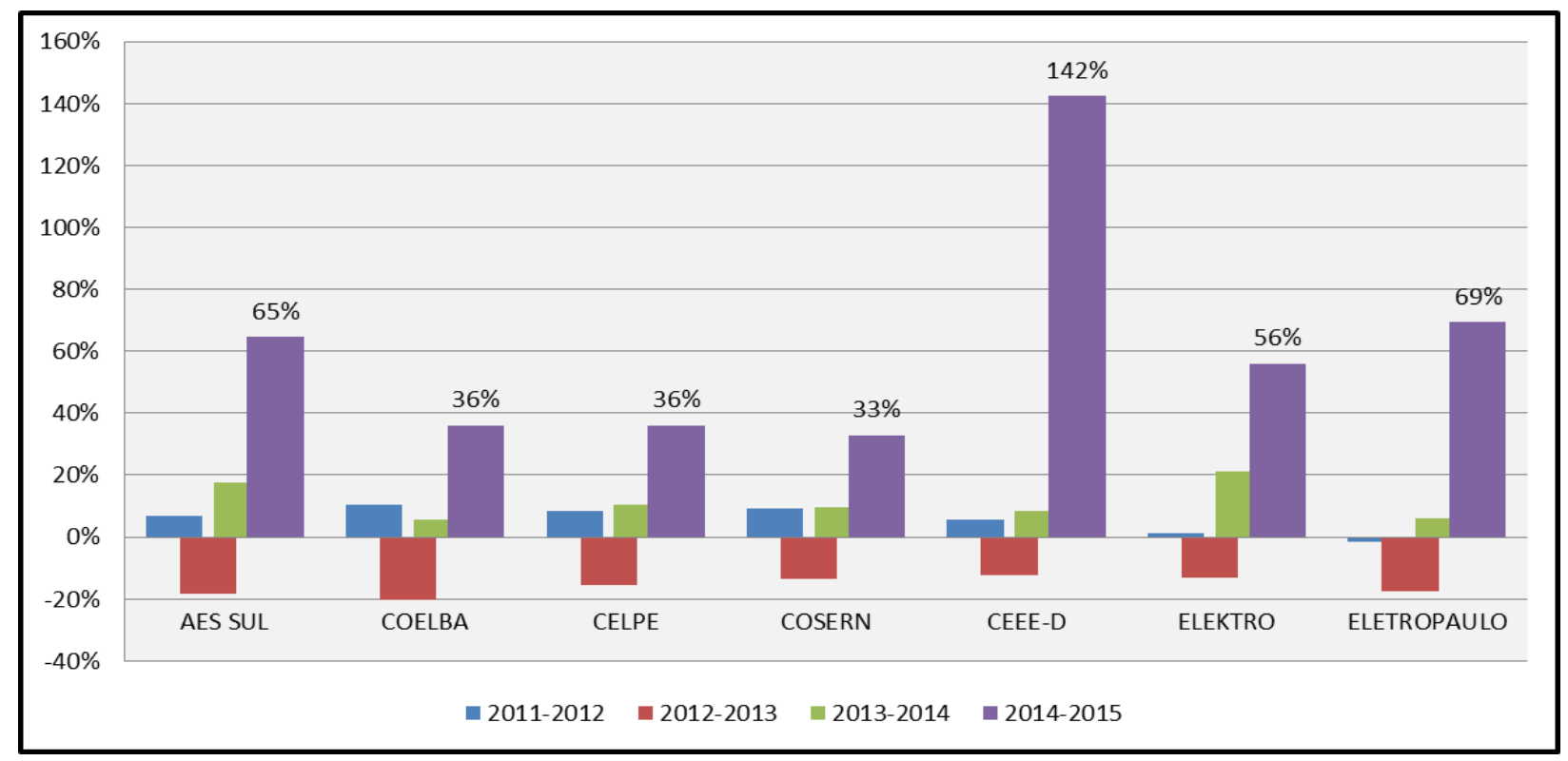

Figura 12. Variações do preço médio de venda de energia no mercado cativo

Fonte: Elaborado pelos autores, com base nas informações coletadas dos relatórios anuais.

A partir da análise da Figura 12, pode-se verificar que o preço médio da energia vendida no mercado cativo ou, analisando por outra vertente, o preço da energia pago pelo consumidor final sofreu drástica variação no ano de 2015 em comparação com 2014. Essa elevação decorre do repasse de custos acumulados na cadeia produtiva e, 
Os reflexos da crise hídrica brasileira na estrutura de custos das empresas do setor de energia elétrica

Ângelo Wesley de Sousa Falcão, Rosângela Venâncio Nunes, Charles Washington Costa de Assis, Nayana de Almeida Adriano, Alexandra Alencar Siebra

como exposto nos relatórios anuais das empresas, do reajuste de tarifas de comercialização de energia elétrica.

Conclui-se que, para o consumidor do mercado cativo, o principal reflexo da crise hídrica foi a elevação (ou variação desfavorável) do preço de compra de energia elétrica, em suma, no ano de 2015.

\section{CONSIDERAÇÕES FINAIS}

Ao se analisar os relatórios anuais e de sustentabilidade, verificou-se que a grande maioria das empresas não evidenciou indicadores operacionais relevantes para uma apresentação completa da empresa aos seus stakeholders. Apesar disso, a análise dos relatórios das 15 empresas que apresentaram os indicadores relevantes ao estudo possibilitou mostrar, com êxito, que a crise hídrica produziu reflexos significativos na cadeia de suprimentos do setor elétrico brasileiro. Complementando os resultados obtidos na análise de Silva (2015), constatou-se, a partir da análise econômica, que as empresas do setor elétrico que apresentavam cenários desfavoráveis até 2013, passaram a reagir à crise nos anos seguintes, apresentando, em média, variações econômicas favoráveis e balanceadas nas variáveis e indicadores que expressam a rentabilidade.

De modo geral, quando comparado o período durante a crise hídrica ao anterior à crise, verificou-se que as empresas de geração apresentaram variações favoráveis em seus indicadores econômicos, desfavoráveis em seus indicadores operacionais e crescentes e estáveis na geração de riqueza. As empresas transmissoras apresentaram variações econômicas e operacionais favoráveis e variações crescentes e estáveis na riqueza gerada. Já as empresas distribuidoras apresentaram variações balanceadas nos indicadores econômicos, com variações favoráveis e desfavoráveis proporcionais e, na média geral, variações favoráveis em seus indicadores operacionais, tornando-se o 
Os reflexos da crise hídrica brasileira na estrutura de custos das empresas do setor de energia elétrica

Ângelo Wesley de Sousa Falcão, Rosângela Venâncio Nunes, Charles Washington Costa de Assis, Nayana de Almeida Adriano, Alexandra Alencar Siebra

conciliador dos custos acumulados da cadeia e dos preços de venda de energia ao consumidor final.

Para o consumidor final do mercado cativo, o reflexo foi o aumento nos preços de compra de energia elétrica, verificado por modalidade de consumidor, acarretado pelo repasse de custos ao longo da cadeia e, certamente, pelos reajustes das tarifas de comercialização de energia elétrica, conforme verificado nos relatórios analisados.

Em uma análise ampla, a pesquisa respondeu ao problema proposto e atingiu seu objetivo geral, já que demonstrou, por meio de gráficos e tabelas, os reflexos nas variáveis que compõem a estrutura de custos da cadeia produtiva do setor elétrico ao longo dos anos da crise hídrica brasileira.

Como restrições encontradas na pesquisa, pode-se mencionar a impossibilidade de análise de todo o universo de empresas que compõem a cadeia produtiva do setor elétrico brasileiro, pelo fato de grande parcela não ter disponível, em seus websites ou no site da $\mathrm{B} 3$, todos os relatórios necessários do período analisado no momento em que foi realizada a coleta dos dados. Dessa forma, as conclusões estão limitadas às empresas, aos anos e aos indicadores analisados. Outra limitação é que não se pode afirmar que os resultados referentes ao comportamento dos indicadores foram exclusivamente afetados pela crise hídrica, pois o ambiente macroeconômico envolve outras variáveis que não foram foco deste estudo. Além disso, pode-se citar, também, a limitação encontrada quanto a bibliografias, com pouca disponibilidade de pesquisas envolvendo análises quantitativas da cadeia de suprimentos do setor elétrico brasileiro.

Como sugestão para pesquisas futuras, sugere-se analisar os reflexos da crise hídrica brasileira para a cadeia produtiva do setor elétrico com aspectos essencialmente quantitativos mais aprofundados.

\section{REFERÊNCIAS}

ABRADEE - Associação Brasileira de Distribuidores de Energia Elétrica. Visão Geral do Setor. Recuperado de: <http://www.abradee.com.br/setor-eletrico/visao-geral-dosetor>. Acesso em: 26/mar./2016. 
Os reflexos da crise hídrica brasileira na estrutura de custos das empresas do setor de energia

elétrica

Ângelo Wesley de Sousa Falcão, Rosângela Venâncio Nunes, Charles Washington Costa de Assis, Nayana de Almeida Adriano, Alexandra Alencar Siebra

Almeida, D. L., \& Benassi, R. F. (2015). Crise hídrica e de energia elétrica entre 20142015 na região Sudeste. Revista hipótese. Itapetininga, n. 2, p. 65-76. Recuperado de: <http://itp.ifsp.edu.br/ojs/index.php/HIP/article/view/88>. Acesso em: 20/mar./ 2016 .

ANEEL - Agência Nacional de Energia Elétrica. (2016). Acompanhe a evolução das bandeiras tarifárias.

Recuperado de: $<$ http://www2.aneel.gov.br/aplicacoes/noticias/Output_Noticias.cfm?Identidade=906 3\&id_area=90 >. Acesso em: 03/abr./2016.

Bardin, L. (1977). Análise de Conteúdo. Lisboa-Portugal: Edições 70, Lda.

Beuren, I. M., \& Marcello, I. E. (2016). Relação da importância dos recursos estratégicos com as medidas de desempenho em empresas brasileiras. Revista Ibero-Americana de Estratégia. V. 15, n. 1, jan./mar. Recuperado de: <http://www.revistaiberoamericana.org/ojs/index.php/ibero/issue/current>. Acesso em: 30/abr./2016.

BRASIL. (2015). Ministério do Meio ambiente. Água. Brasília. Recuperado de: <http://www.mma.gov.br/agua>. Acesso em: 19/mar./2016.

. Empresa de Pesquisa Energética. Balanço Energético Nacional 2013: Ano base 2012. Rio de Janeiro: EPE, 2013.2 Recuperado de:<https://ben.epe.gov.br/downloads/Relatorio_Final_BEN_2013.pdf>. Acesso em: 24/abr./2016.

. Empresa de Pesquisa Energética. Balanço Energético Nacional 2014: Ano base 2013. Rio de Janeiro: EPE, $2014 . \quad$ Recuperado de:<https://ben.epe.gov.br/downloads/Relatorio_Final_BEN_2014.pdf>. Acesso em: 24/abr./2016.

. Empresa de Pesquisa Energética. Balanço Energético Nacional 2015: Ano base 2014. Rio de Janeiro: EPE, 2015. Recuperado de: $<$ https://ben.epe.gov.br/downloads/Relatorio_Final_BEN_2015.pdf >. Acesso em: 26/mar./2016.

Callado, A. A., Callado A. L. C., Moller, H. D., Neutzling, D. M. (2009). Indicadores de desempenho social corporativo: um estudo entre empresas do setor elétrico. Revista e Gestão. São Paulo, v. 5, n. 1, p. 71-93, jan./mar. Recuperado de: <http://www.unisantos.br/mestrado/gestao/egesta/artigos/170.pdf >. Acesso em: 30/abr./2016. 
Os reflexos da crise hídrica brasileira na estrutura de custos das empresas do setor de energia

elétrica

Ângelo Wesley de Sousa Falcão, Rosângela Venâncio Nunes, Charles Washington Costa de Assis, Nayana de Almeida Adriano, Alexandra Alencar Siebra

Cazarré, M. (2016). País desperdiça 36,4\% da água disponível, diz ministério. Brasília. Recuperado de: <http://agenciabrasil.ebc.com.br/geral/noticia/2016-03/paisdesperdica-364-da-agua-disponivel-diz-ministerio>. Acesso em: 27/mar./2016.

Chiavenato, I. (2014). Gestão financeira: uma abordagem introdutória. (3a ed.). São Paulo: Manole.

Dias, T. F. (2008) Avaliação de indicadores operacionais: Estudo de caso de uma empresa do setor Ferroviário. (Trabalho de Conclusão de Curso de Graduação). Universidade Federal de Juiz de Fora - UFJF, Juiz de Fora, Minas Gerais. Recuperado de: <http://www.ufff.br/ep/files/2014/07/2008_3_Thiago.pdf>. Acesso em: 06/jun./2016.

Durski, G. R. (2003). Avaliação do desempenho em cadeias de suprimentos. Revista da FAE. Curitiba, v. 6, n. 1, p. 27-28, jan./abr. Recuperado de: $<$ http://www.fae.edu/publicacoes/pdf/revista_da_fae/fae_v6_n1/03_gislene.pdf>. Acesso em: 06/jun./2016.

Galvão, J., \& Bermann, C. (2015) Crise hídrica e energia: conflitos no uso múltiplo das águas. Revista Estudos Avançados. São Paulo, v. 29, n. 84, p. 43-68. Recuperado de: <http://www.revistas.usp.br/eav/article/view/104941>. Acesso em: 17/abr./2016.

Gitman, L. J. (2010). Princípios de administração financeira. (12a ed.). São Paulo: Pearson Prentice Hall.

Goldemberg, J. (2015). O estado atual do setor elétrico brasileiro. Revista USP. São Paulo, n. 104, p. 37-44. Recuperado de: <http://www.revistas.usp.br/revusp/article/view/106751>. Acesso em: 13/mar./2016.

GRI - Global Reporting Initiative. (2013). Diretrizes para relatórios de sustentabilidade. Recuperado de: <https://www.globalreporting.org/resourcelibrary/Brazil-PortugueseG3.1-Reporting-Guidelines.pdf>. Acesso em: 05/maio/2016.

GRI - Global Reporting Initiative. (2015). Diretrizes para relato de sustentabilidade. Recuperado de: <https://www.globalreporting.org/resourcelibrary/BrazilianPortuguese-G4-Part-One.pdf>. Acesso em: 06/jun./2016.

Pena, R. F. Escassez de água no Brasil. Brasil Escola. Recuperado de: $<$ http://brasilescola.uol.com.br/geografia/escassez-agua-no-brasil.htm>. Acesso em: 27/mar./2016. 
Os reflexos da crise hídrica brasileira na estrutura de custos das empresas do setor de energia elétrica

Ângelo Wesley de Sousa Falcão, Rosângela Venâncio Nunes, Charles Washington Costa de Assis, Nayana de Almeida Adriano, Alexandra Alencar Siebra

Pereira Filho, A. S. J. (2014). Análise da escassez hídrica brasileira em 2014. Revista USP. São Paulo, n. 104, p. 125-132, 2015. Recuperado de: <http://www.revistas.usp.br/revusp/article/view/106760>. Acesso em: 27/mar./2016.

Silva, P. Z. P. (2015). Análise da crise de 2012 no desempenho econômico-financeiro das indústrias de energia elétrica listadas na BM\&F Bovespa. Revista ConTexto. Porto Alegre, v. 15, n. 31, p. 67-80, set./dez. Recuperado de: <http://seer.ufrgs.br/index.php/ConTexto/index>. Acesso em: 29/abr./2016.

Silverman, D. (2009). Interpretação de dados qualitativos: métodos para análise de entrevistas, textos e interações. (3a ed.). Porto Alegre: Artmed.

Taffarel, M., Silva, W. V., \& Clemente, A. (2013) Risco regulatório e reação do mercado: análise do setor de energia elétrica brasileiro. Revista Universo Contábil. Blumenau, v. $9, \quad$ n.1, p. 121-134, jan./mar. Recuperado de:<http://proxy.furb.br/ojs/index.php/universocontabil/article/view/2722/2214>. Acesso em: 24/jun./2016.

Uniethos. (2016). Relatório de Sustentabilidade GRI, G4. 2014. Recuperado de: <http://www.siteuniethos.org.br/2013/07/relatorio-de-sustentabilidade-gri-g4/>. Acesso em: 25/mai./2016.

Data de Submissão: 01/02/2018

Data de Aceite: 23/07/2019 